\title{
What do we learn about bromoform transport and chemistry in deep convection from fine scale modelling?
}

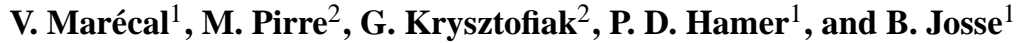 \\ ${ }^{1}$ Centre National de Recherches Météorologiques-Groupe d'étude de l'Atmosphère Météorologique, \\ Météo-France and CNRS, URA1357, Toulouse, France \\ ${ }^{2}$ Laboratoire de Physique et Chimie de l'Environnement et de l'Espace, CNRS and University of Orléans, \\ UMR7328, Orléans, France
}

Correspondence to: V. Marécal (virginie.marecal@meteo.fr)

Received: 29 June 2011 - Published in Atmos. Chem. Phys. Discuss.: 2 November 2011

Revised: 25 June 2012 - Accepted: 26 June 2012 - Published: 16 July 2012

\begin{abstract}
Bromoform is one of the most abundant halogenated Very Short-Lived Substances (VSLS) that possibly contributes, when degradated, to the inorganic halogen loading in the stratosphere. In this paper we present a detailed modelling study of the transport and the photochemical degradation of bromoform and its product gases (PGs) in a tropical convective cloud. The aim was to explore the transport and chemistry of bromoform under idealised conditions at the cloud scale. We used a 3-D cloud-resolving model coupled with a chemistry model including gaseous and aqueous chemistry. In particular, our model features explicit partitioning of the PGs between the gas phase and the aqueous phase based on newly calculated Henry's law coefficients using theoretical methods. We ran idealised simulations for up to 10 days that were initialised using a tropical radiosounding of atmospheric conditions and using outputs from a global chemistry-transport model for chemical species. Two simulations were run with stable atmospheric conditions with a bromoform initial mixing ratio of $40 \mathrm{pptv}$ (part per trillion by volume) and $1.6 \mathrm{pptv}$ up to $1 \mathrm{~km}$ altitude. The first simulation corresponds to high bromoform mixing ratios that are representative of real values found near strong localised sources (e.g. tropical coastal margins) and the second to the global tropical mean mixing ratio from observations. Both of these simulations show that the sum of bromoform and its PGs significantly decreases with time because of dry deposition, and that PGs are mainly in the form of $\mathrm{HBr}$ after 2 days of simulation. Two further simulations are conducted; these are similar to the first two simulations but include perturbations of temperature and moisture leading to the development
\end{abstract}

of a convective cloud reaching the tropical tropopause layer (TTL). Results of these simulations show an efficient vertical transport of the bromoform from the boundary layer to the upper troposphere and the TTL. The bromoform mixing ratio in the TTL is up to $45 \%$ of the initial boundary layer mixing ratio. The most abundant organic PGs, which are not very soluble, are also uplifted efficiently in both simulations featuring the convective perturbation. The inorganic PGs are more abundant than the organic PGs, and their mixing ratios in the upper troposphere and in the TTL depend on the partitioning between inorganic soluble and insoluble species in the convective cloud. Important soluble species such as $\mathrm{HBr}$ and $\mathrm{HOBr}$ are efficiently scavenged by rain. This removal of $\mathrm{Br}_{\mathrm{y}}$ by rain is reduced by the release of $\mathrm{Br}_{2}$ (relatively insoluble) to the gas phase due to aqueous chemistry processes in the cloud droplets. The formation of $\mathrm{Br}_{2}$ in the aqueous phase and its subsequent release to the gas phase makes a non negligible contribution to the high altitude bromine budget in the case of the large bromoform ( $40 \mathrm{pptv}$ ) initial mixing ratios. In this specific, yet realistic case, this $\mathrm{Br}_{2}$ production process is important for the PG budget in the upper troposphere and in the TTL above convective systems. This process is favoured by acidic conditions in the cloud droplets, i.e. polluted conditions. In the case of low bromoform initial mixing ratios, which are more representative of the mean distribution in the tropics, this $\mathrm{Br}_{2}$ production process is shown to be less important. These conclusions could nevertheless be revisited if the knowledge of chlorine and bromine chemistry in the cloud droplets was improved in the future. 


\section{Introduction}

Very short-lived halogenated substances (VSLS) have been the focus of many studies recently because they likely contribute, through their transport and photochemical degradation, to the inorganic bromine loading in the stratosphere and consequently influence its ozone budget (Montzka et al., 2011). The estimation of the part of the stratospheric inorganic bromine which comes from VSLS varies from less than 1 pptv up to greater than 8 pptv, depending on the type of measurements (balloon-borne, e.g. Dorf et al., 2008, satellite, e.g. Sinnhuber et al., 2005) or of the model used (e.g. Gettelman et al., 2009; Aschmann et al., 2009). The VSLS source gases (SGs) and their product gases (PGs) effects on the stratospheric bromine loading depend on their emissions, transport, chemistry, dry deposition and wash out. The chemical processing of SGs and PGs includes gaseous chemistry, photolysis, hydrolysis, aqueous chemistry and interactions with atmospheric ice particles.

The tropical region is of great interest for VSLS because VSLS are mainly emitted from the warm tropical oceans. Moreover, like other chemical species and aerosols, SGs and PGs mainly enter the stratosphere in the tropics. The main pathway is the rapid vertical transport by deep convection into the TTL (Tropical Tropopause Layer, see review paper by Fueglistaler et al., 2009) followed by a slow radiative ascent into the stratosphere for air having reached at least the level of zero radiative heating (LZRH, $\sim 15.5 \mathrm{~km}$ altitude, $360 \mathrm{~K}$ ). Deep convection is therefore a key process for the evolution of SGs and PGs in the troposphere before they possibly reach the stratosphere. Convection can lift the emissions of SGs and the PGs from the boundary layer into the TTL within a few hours. It can also influence the PGs budget through interactions between gaseous species and hydrometeors, in particular, by the scavenging of soluble organic and inorganic PGs.

The model studies conducted so far on VSLS are either based on 1-D (one-dimensional) models (Gettelman et al., 2009), or on Lagrangian models (e.g. Brioude et al., 2010; Pisso et al., 2010; Schofield et al., 2011), or on 3D (three-dimensional) global models (e.g. Aschmann et al., 2009; Hossaini et al., 2010, 2012; Aschmann et al., 2011). They mainly seek to estimate the global impact of VSLS on stratospheric halogen loading and ozone. Because of the large number and the complexity of the processes involved in the chemical processing of VSLS and PGs, modelling studies generally use simplifications. Among the VSLS, bromoform $\left(\mathrm{CHBr}_{3}\right)$ and dibromomethane $\left(\mathrm{CH}_{2} \mathrm{Br}_{2}\right)$ are studied the most often because they are the most abundant (Montzka et al., 2011). A detailed chemical scheme for $\mathrm{CHBr}_{3}$ and $\mathrm{CH}_{2} \mathrm{Br}_{2}$ degradation was proposed by Hossaini et al. (2010). They implemented this scheme in the 3-D TOMCAT/SLIMCAT global chemistry transport model and showed that the organic PG abundance is small at the global scale. This indicates that SG degradation can reasonably be assumed to lead immediately to inorganic bromine on a global scale. They estimated that $\mathrm{CHBr}_{3}$ and $\mathrm{CH}_{2} \mathrm{Br}_{2}$ provide $\sim 2.4 \mathrm{pptv}$ of the inorganic bromine of the lower stratosphere with SG injection being the dominant pathway. Several recent studies showed the important role of deep convection on the halogen loading in the upper troposphere and lower stratosphere (Gettelman et al., 2009; Brioude et al., 2010; Hossaini et al., 2010; Pisso et al., 2010; Aschmann et al., 2011). 3-D-global models or Lagrangian models generally use on-line or off-line output fluxes from convection parameterizations to represent tracer transport by convection. But it is well known that there are large uncertainties on the tracer transport in deep convection parameterizations (e.g. Zhang et al., 2008; Arteta et al., 2009; Hoyle et al., 2011). The interactions between trace gases and hydrometeors (aqueous chemistry, hydrolysis, ice adsorption and associated washout) are usually represented in a simple manner in models using parameterized deep convection. For instance, Hossaini et al. (2010) assume that $\mathrm{Br}_{\mathrm{y}}$ (inorganic bromine species) is removed in the troposphere by washout with a specified lifetime. This lifetime is a source of uncertainty in their calculations. In Aschmann et al. (2011), they improved the model by taking into account the heterogeneous activation reactions of dissolved/adsorbed bromine species on liquid aerosols, NAT (solid nitric acid trihydrate) and ice particles. They showed that there is very little removal of inorganic $\mathrm{Br}_{\mathrm{y}}$ by ice sedimentation in the TTL.

Detailed studies at the fine scale are among the possible approaches to assess and to improve upon the assumptions used in global models simulating halogenated VSLS chemistry. For example, with regards to deep convection parameterizations our model has a sufficiently fine scale to explicitly resolve convective processes. In this context, the objective of the paper is to analyse at the local scale the impact of a tropical deep convective cloud on $\mathrm{CHBr}_{3}$ and on its organic and inorganic PGs. The limitations of the methodology employed here prevent us from making conclusions about the impact of these processes on the global budget of $\mathrm{CHBr}_{3}$ and its PGs. Here we analyse results of cloud-resolving model simulations with on-line detailed gaseous and aqueous chemistry of bromoform for an idealized deep convective cloud. In particular, we discuss processes that were not treated before: the $\mathrm{Br}_{2}$ production in the gas phase from aqueous chemistry in the cloud droplets, and the removal of organic PGs by wet deposition mediated by newly calculated Henry's law coefficients. The descriptions of the model and of the simulation setup are given in Sect. 2. The results are analysed in Sect. 3. Conclusions are given in Sect. 4. 


\section{Model description and simulation set-up}

\subsection{Meteorology: model and setup}

The model used here is the 3-D-limited area model CATTBRAMS (Coupled Aerosol Tracer Transport-Brazilian Regional Atmospheric Modeling system, Freitas et al., 2009) coupled on-line with a chemistry model. CATT-BRAMS is a numerical model designed to simulate atmospheric circulations at many scales and the associated transport of tracers. It is based on the Regional Atmospheric Modeling System - RAMS (Walko et al., 2000) version 6. RAMS solves the fully compressible non-hydrostatic equations described by Tripoli and Cotton (1982). It has a set of state-of-art physical parameterizations appropriate to simulate processes, such as surface-air exchanges, turbulence, convection, radiation and cloud microphysics.

For our fine scale study we use a cloud-resolving configuration with a $1 \mathrm{~km}$ horizontal resolution and a $100 \times 100 \mathrm{~km}$ domain. We use 48 vertical levels spanning from the surface up to $24.5 \mathrm{~km}$ altitude. The vertical grid spacing is $\sim 200 \mathrm{~m}$ in the boundary layer, $500 \mathrm{~m}$ in the free troposphere and in the TTL (up to $18 \mathrm{~km}$ altitude) and $1 \mathrm{~km}$ in the lower stratosphere. For this first study of $\mathrm{CHBr}_{3}$ and its PGs at the cloud scale, we chose a simple meteorological framework to represent the development of a deep convective cloud in the tropical atmosphere. At the initial time, the model meteorological variables (pressure, temperature and relative humidity) are assumed to be uniform horizontally. They are initialised vertically using a tropical radiosounding launched from Darwin (Australia, latitude $=12.1^{\circ} \mathrm{S}$ and longitude $=130.9^{\circ} \mathrm{E}$ ) on 16 November 2005 at 23:00 UTC during the wet season in the frame of the SCOUT-O3 European Project (http://www.ozone-sec.ch.cam.ac.uk/scout_o3). Note that Darwin is located in the Maritime Continent, which is a region of high-reaching convection and concomitant exceptionally cold tropopause temperatures. It is also located close to a warm ocean coastal region where natural bromoform emissions are expected to be strong (e.g. Quack and Wallace, 2003). The radiosounding chosen corresponds to atmospheric stable conditions. We ran 2 kinds of simulations each of 10-days in duration, which is approximately the lifetime of $\mathrm{CHBr}_{3}$ in summer tropical conditions. The first type, called BG, are background simulations corresponding to stable atmospheric conditions throughout the whole simulation. No clouds develop during the BG simulations. In the other kind of simulations, called PERT hereafter, deep convection is forced to develop by adding perturbations of moisture and of temperature in the middle of the domain. The perturbation is applied to an area of $30 \mathrm{~km}$ radius. It is written:

$\frac{\mathrm{d} r v}{\mathrm{~d} t}=\Delta r v_{0} \cos ^{2}\left(\frac{\pi \mathrm{d}}{60}\right)$ and $\frac{\mathrm{d} T}{\mathrm{~d} t}=\Delta T_{0} \cos ^{2}\left(\frac{\pi \mathrm{d}}{60}\right)$

where "d" is the distance $(\mathrm{km})$ from the centre of the perturbation, $\Delta r v_{0}=3.5 \times 10^{-3} \mathrm{~g} \mathrm{~kg}^{-1} \mathrm{~s}^{-1}$ and $\Delta T_{0}=$
$0.025 \mathrm{~K} \mathrm{~s}^{-1}$. This perturbation is applied for $800 \mathrm{~s}$ in the first $2 \mathrm{~km}$ of the atmosphere after 5 days and $6 \mathrm{~h}$ of simulation (14:00 LT). This allows the deep convective cloud to start developing in the afternoon as expected in the tropics. Cyclic boundary conditions are used. To represent microphysical processes we use the single-moment bulk parameterization proposed by Walko et al. (1995) in which seven types of hydrometeors are taken into account: cloud, rain, pristine ice, snow, aggregates, graupel and hail. The radiative code of the Community Aerosol and Radiation Model for Atmospheres (CARMA, Toon et al., 1989) is used for the radiation scheme, which takes into account the effect of hydrometeors and aerosols on radiation. Turbulent mixing is treated according to Mellor and Yamada (1982), which employs the turbulence kinetic energy as a prognostic variable. The turbulence kinetic energy is the mean kinetic energy per unit mass associated with eddies in turbulent flow.

\subsection{Chemistry model}

The chemistry model coupled on-line with the CATTBRAMS includes gaseous chemistry, photolysis, $\mathrm{BrONO}_{2}$ hydrolysis, aqueous chemistry of bromine species and dry deposition. As justified in Sect. 3.2, it does not include the interactions of the chemical species with the ice particles. The general chemical system of equations used is:

$$
\begin{aligned}
\frac{\mathrm{d} X_{\mathrm{g}}}{\mathrm{d} t} & =-k_{X_{\mathrm{C}}} V_{\mathrm{C}} X_{\mathrm{g}}-k_{X_{\mathrm{R}}} V_{\mathrm{R}} X_{\mathrm{g}}+\frac{k_{X_{\mathrm{C}}} X_{\mathrm{C}}}{R T H_{X}}+\frac{k_{X_{\mathrm{R}}} X_{\mathrm{R}}}{R T H_{X}} \\
& -D_{X_{\mathrm{dep}}}+P_{X_{\mathrm{g}}}-L_{X_{\mathrm{g}}} X_{\mathrm{g}} \\
\frac{\mathrm{d} X_{\mathrm{C}}}{\mathrm{d} t} & =k_{X_{\mathrm{C}}} V_{\mathrm{C}} X_{\mathrm{g}}-\frac{k_{X_{\mathrm{C}} X_{\mathrm{C}}}}{R T H_{X}}+P_{X_{\mathrm{C}}}-L_{X_{\mathrm{C}}} X_{\mathrm{C}} \\
\frac{\mathrm{d} X_{\mathrm{R}}}{\mathrm{d} t} & =k_{X_{\mathrm{R}}} V_{\mathrm{R}} X_{\mathrm{g}}-\frac{k_{X_{\mathrm{R}}} X_{\mathrm{R}}}{R T H_{X}}+P_{X_{\mathrm{R}}}-L_{X_{\mathrm{R}}} X_{\mathrm{R}}
\end{aligned}
$$

where

- $X_{\mathrm{g}}$ is the concentration of species $X$ in the gas phase in molecules per $\mathrm{cm}^{3}$ of air,

- $X_{\mathrm{C}}\left(\right.$ resp. $\left.X_{\mathrm{R}}\right)$ is the concentration of species $X$ in the cloud droplets (resp. raindrops) in molecules per $\mathrm{cm}^{3}$ of air,

- $V_{\mathrm{C}}$ and $V_{\mathrm{R}}$ are the volume densities of cloud and of rain in $\mathrm{m}^{3}$ water $\mathrm{m}^{-3}$ air computed from their mass mixing ratios,

- $k_{X_{\mathrm{C}}}$ (resp. $k_{X_{\mathrm{R}}}$ ) in $\mathrm{s}^{-1}$ is the mass transfer between the gas and the cloud droplets (resp. raindrops) of species $X$,

- $H_{X}$ is the effective Henry's constant of species $X$ in $\mathrm{moll}^{-1} \mathrm{~atm}^{-1}$,

- $R$ is the universal gas constant in 1 atm $\mathrm{mol}^{-1} \mathrm{~K}^{-1}$, 
- $T$ is the temperature in $\mathrm{K}$,

- $P_{X_{\mathrm{C}}}$ term (resp. $P_{X_{\mathrm{R}}}$ term) is the production term in the cloud droplets (resp. raindrops) of species $X$,

- $L_{X_{\mathrm{C}}}$ (resp. $L_{X_{\mathrm{R}}}$ ) is the loss term of species $X$ in the cloud droplets (resp. raindrops),

- $P_{X_{\mathrm{g}}}$ and $L_{X_{\mathrm{g}}}$ terms are the production and loss terms of species $X$ in the gas phase including also hydrolysis,

- $D_{X_{\text {dep }}}$ term is the dry deposition of species $X$ in the lowest model level.

In the case of non soluble species only Eq. (1) is solved and only the last two terms of Eq. (1) are taken into account.

The gaseous chemistry model includes the chemistry for $\mathrm{CO}, \mathrm{CH}_{4}, \mathrm{O}_{3}, \mathrm{NO}_{\mathrm{y}}, \mathrm{HO}_{\mathrm{x}}$ (Barth et al., 2007), $\mathrm{Br}_{\mathrm{y}}$, and organic chemistry of the degradation of $\mathrm{CHBr}_{3}$ (Hossaini et al., 2010). $\mathrm{Cl}_{\mathrm{y}}$ (inorganic chlorine species) and NMHC (nonmethane hydrocarbons) chemistry are not included to save computing time. $\mathrm{Cl}_{\mathrm{y}}$ chemistry has an impact on the bromine chemistry in the aqueous phase. As shown in Sect. 3.2.2, this impact depends, however, on uncertain factors. Sensitivity tests will be nevertheless performed to show the possible impact of these uncertain aspects of chlorine chemistry. Chlorine chemistry also has an impact on the lifetime of $\mathrm{CHBr}_{3}$ and therefore the production of PGs. The rate constant of the reaction $\mathrm{Cl}+\mathrm{CHBr}_{3} \rightarrow \mathrm{HCl}+\mathrm{CBr}_{3}$ is approximately 1.5 times larger than the rate constant of the reaction $\mathrm{OH}+\mathrm{CHBr}_{3} \rightarrow \mathrm{H}_{2} \mathrm{O}+\mathrm{CBr}_{3}$ in the lower atmosphere. $\mathrm{Cl}$ concentrations in the lower atmosphere are between $10^{3}$ to $10^{6} \mathrm{~cm}^{-3}$ (Chang et al., 2004; Finlayson-Pitts, 1993) while $\mathrm{OH}$ concentrations are higher than $10^{6} \mathrm{~cm}^{-3}$. For most cases the degradation of $\mathrm{CHBr}_{3}$ by chlorine can be therefore neglected. In cases of large concentrations of the $\mathrm{Cl}$ radical, it is however comparable to the degradation by $\mathrm{OH}$. Since in both cases the organic bromine product of the reactions is the same $\left(\mathrm{CBr}_{3}\right)$, it is equivalent to take into account the degradation of $\mathrm{CHBr}_{3}$ by $\mathrm{Cl}$ or to increase artificially the concentration of $\mathrm{OH}$.

The lack of NMHC chemistry can significantly affect $\mathrm{HO}_{\mathrm{x}}$ precursors and therefore $\mathrm{HO}_{\mathrm{x}}$ concentrations, but mainly in the upper troposphere (Jaeglé et al., 2001). In our study gaseous chemistry is only important in the lower troposphere. For $\mathrm{CHBr}_{3}$, the gas phase reactions proposed in Hossaini et al. (2010) are used. In addition, the rate constants of the organic chemistry of $\mathrm{CHBr}_{3}$ are from Hossaini et al. (2010). Other gaseous rate constants and cross-sections are from JPL (Sander et al., 2006) and IUPAC (IUPAC Subcommittee on Gas Kinetic Data Evaluation, Atkinson et al., 2007; http:// www.iupac-kinetic.ch.cam.ac.uk). Photolysis rates are computed on-line using the Fast-TUV model (Tie et al., 2003) in order to take into account the effect of clouds on photolysis rates in an interactive way. The photolysis cross-sections are from JPL (Sander et al., 2006) and IUPAC (Atkinson et al., 2007).
The model includes the hydrolysis reaction of $\mathrm{BrONO}_{2}$ on the cloud droplets and raindrops leading to the formation of $\mathrm{HOBr}$ :

$\mathrm{BrONO}_{2}+\mathrm{H}_{2} \mathrm{O} \rightarrow \mathrm{HOBr}+\mathrm{HNO}_{3}$

The rate constant $k_{1 \mathrm{C}}$ (resp. $k_{1 \mathrm{R}}$ ) of Reaction (R1) in the cloud droplets (resp. the raindrops) is computed using the mean mixing ratio and the mean-mass radius of cloud droplets (resp. raindrops) from the bulk-microphysical scheme. Following Yang et al. (2005) they are written:

$k_{1 \mathrm{C}}=\frac{V_{\mathrm{C}}}{\left(\frac{r_{\mathrm{C}}^{2}}{3 D_{\mathrm{g}}}+\frac{4 r_{\mathrm{C}}}{3 v \gamma}\right)}$ and $k_{1 \mathrm{R}}=\frac{V_{\mathrm{R}}}{\left(\frac{r_{\mathrm{R}}^{2}}{3 D_{\mathrm{g}}}+\frac{4 r_{\mathrm{R}}}{3 v \gamma}\right)}$

where:

- $r_{\mathrm{C}}$ (resp. $r_{\mathrm{R}}$ ) is the mean-mass radius of the cloud droplets (resp. raindrops) size distribution. $r_{\mathrm{C}}$ is computed by the microphysical scheme of the model and depends on the grid point and on time. It is typically $10 \mu \mathrm{m} . r_{\mathrm{R}}$ is fixed to $250 \mu \mathrm{m}$ in the microphysical scheme.

$-v$ is the thermal velocity of $\mathrm{BrONO}_{2}$,

- $D_{\mathrm{g}}$ is the gas phase diffusivity of $\mathrm{BrONO}_{2}$ in air: $D_{\mathrm{g}}=$ $\lambda v / 3$ where $\lambda$ is the mean free path which is assumed to be $\lambda=0.1 \mu \mathrm{m}$ (Sander and Crutzen, 1996),

$-\gamma$ is the accommodation coefficient. It is assumed to be: $\gamma=0.3$ (Yang et al., 2005).

The model takes into account the effect on chemical species of condensation, water vapour deposition, evaporation and sedimentation. These microphysical processes are estimated by the bulk microphysical scheme. It also includes the reversible kinetic transfer of species from the gas phase to the cloud droplets and raindrops (controlled by the effective Henry's and accommodation constants) and the transfer of species from cloud droplets to raindrops during the coalescence process and to the ice particles during the riming process. The retention coefficient used in the transfer from cloud to ice particles is assumed to be equal to 1 for all species. Once in the ice particles, the chemical species are assumed to be lost by wash out. This last assumption is realistic because the ice particles mainly grow by riming in the simulation and form fast-falling graupel and hail particles. Some of them could nevertheless be transported by convection up to the TTL where they could evaporate, releasing chemical species in the gas phase. Taking into account this process would require following numerically the concentration of the chemical species in the five ice categories of the microphysical scheme. It has not been taken into account in the simulation to save computing time.

The Henry's constants used in the model are mainly from Sander (1999). Table 1 gives the Henry's constants for the 
Table 1. Accommodation coefficients and values used in the determination of the effective Henry's constants $H_{X}^{1}$ of bromine species $X$ used in the model.

\begin{tabular}{|c|c|c|c|c|c|}
\hline Species & $\alpha^{6}$ & $\begin{array}{l}H_{298} \\
\left(\mathrm{moll}^{-1} \mathrm{~atm}^{-1}\right)\end{array}$ & $\begin{array}{l}a_{H} \\
(\mathrm{~K})\end{array}$ & $\begin{array}{l}K_{298} \\
\left(\mathrm{moll}^{-1}\right)\end{array}$ & $\begin{array}{l}a_{K} \\
(\mathrm{~K})\end{array}$ \\
\hline $\mathrm{HBr}$ & 0.2 & $0.71^{4}$ & $10200^{4}$ & $1 \times 10^{94}$ & $0^{4}$ \\
\hline $\mathrm{HOBr}$ & 0.2 & $6.1 \times 10^{32}$ & $5900^{3}$ & 0 & 0 \\
\hline $\mathrm{Br}_{2}$ & 0.05 & $0.76^{4}$ & $4177^{4}$ & 0 & 0 \\
\hline $\mathrm{CBr}_{3} \mathrm{OOH}$ & 0.2 & $1.96 \times 10^{55}$ & $5200^{7}$ & 0 & 0 \\
\hline $\mathrm{CHBr}_{2} \mathrm{OOH}$ & 0.2 & $2.25 \times 10^{45}$ & $5200^{7}$ & 0 & 0 \\
\hline $\mathrm{CHBrO}$ & 0.05 & $74^{5}$ & $5800^{8}$ & 0 & 0 \\
\hline $\mathrm{CBr}_{2} \mathrm{O}$ & 0.05 & $21.5^{5}$ & $5400^{8}$ & 0 & 0 \\
\hline $\mathrm{BrCl}$ & 0.05 & $0.94^{2}$ & $5600^{2}$ & 0 & 0 \\
\hline
\end{tabular}

bromine species. The values from Yang et al. (2005) are used for $\mathrm{HBr}$ and $\mathrm{Br}_{2}$. For the hydroperoxides, aldehydes, and ketone organic bromine product gases we used those computed in Krysztofiak et al. (2012). In this paper, the Henry's constants are estimated by the Bond contribution method (BCM) (Meylan and Howard, 1991) and by the Molecular connectivity index (MCI) method (Nirmalakhandan and Speece, 1988). Krysztofiak et al. (2012) show that the MCI method is better at estimating the Henry's law constant for aldehyde and ketone whereas both methods agree on the estimation of the constant for hydroperoxide compounds.

Uncertainties in the Henry's constants calculated by the BCM or MCI methods are evaluated; we achieve this by considering the relative differences between the experimentally measured (Sander et al., 1999) and calculated Henry's constants (BCM and MCI methods) for species of the same family. Acetone is used to represent the ketones family, acetaldehyde the aldehydes and three different hydroperoxides to represent the hydroperoxides. For acetone the difference is $33 \%$, the difference is $12 \%$ for acetaldehyde, and, for hydroperoxides, the difference is $53 \%$ for $\mathrm{CH}_{3} \mathrm{OOH}, 68 \%$ for $\mathrm{C}_{2} \mathrm{H}_{5} \mathrm{OOH}$, and $58 \%$ for $\mathrm{OHCH}_{2} \mathrm{OOH}$. On top of this we take also into account the uncertainties on the experimental measurements (for constants found in Sander et al., 1999): a maximum uncertainty of $44 \%$ (sum of the two types of uncertainties) is evaluated for the bromine ketones and $28 \%$ for bromine aldehydes. Taking into account both types of uncertainties, a mean uncertainty of $70 \%$ is evaluated for bromine hydroperoxides.

The temperature dependencies are derived from $\mathrm{CH}_{3} \mathrm{OOH}$ for hydroperoxide compounds and from averaged values for aldehydes (RCHO) and for ketones (RR'CO) (Sander et al., 1999). The accommodation coefficients are derived from those used in Barth et al. (2001).

The mass transfer between the gas and the liquid droplets takes into account the diffusion in the gas phase and across the droplet interface. Like in many atmospheric chemistry models (e.g. Barth et al., 2003) the diffusion inside cloud and rain droplets is assumed not to be rate limited, meaning that the species are well mixed within the droplets. The mass transfer coefficients $k_{X_{\mathrm{C}}}$ and $k_{X_{\mathrm{R}}}$ are then written:

$$
k_{X_{\mathrm{C}}}=\frac{1}{\left(\frac{r_{\mathrm{C}}^{2}}{3 D_{\mathrm{g} X}}+\frac{4 r_{\mathrm{C}}}{3 v_{X} \alpha_{X}}\right)} \quad k_{X_{\mathrm{R}}}=\frac{1}{\left(\frac{r_{\mathrm{R}}^{2}}{3 D_{\mathrm{g} X}}+\frac{4 r_{\mathrm{R}}}{3 v_{X} \alpha_{X}}\right)}
$$

where $v_{X}$ is the thermal velocity, $D_{\mathrm{g} X}$ the diffusion coefficient in air and $\alpha_{X}$ the accommodation coefficient of species $X$. The mass transfer coefficient for cloud droplets is typically $k_{X_{\mathrm{C}}}=2 \times 10^{5} \mathrm{~s}^{-1}$. It is $k_{X_{\mathrm{R}}}=5 \times 10^{2} \mathrm{~s}^{-1}$ for raindrops.

The model also takes into account the following reactions of $\mathrm{Br}_{\mathrm{y}}$ species in the aqueous phase:

$$
\begin{aligned}
& \mathrm{HOBr}_{\mathrm{aq}}+\mathrm{Br}^{-}+\mathrm{H}^{+} \rightarrow \mathrm{Br}_{2 \mathrm{aq}}+\mathrm{H}_{2} \mathrm{O} \\
& \mathrm{Br}_{2 \mathrm{aq}}\left(+\mathrm{H}_{2} \mathrm{O}\right) \rightarrow \mathrm{HOBr}_{\mathrm{aq}}+\mathrm{Br}^{-}+\mathrm{H}^{+}
\end{aligned}
$$

The rate constants of these reactions are, respectively (Eigen and Kustin, 1962; Fickert et al., 1999): $k_{2}=1.6 \times$ $10^{10} \mathrm{~mol}^{-2} \mathrm{l}^{2} \mathrm{~s}^{-1}, k_{3}=110 \mathrm{~s}^{-1}$. In the literature, Reaction (R2) is taken into account in sulphate aerosols and/or in sea salt aerosols (Von Glasow and Crutzen, 2007). Here we use Reaction (R2) in liquid hydrometeors instead of aerosols. Although Reaction (R3) exists, it has been neglected so far in atmospheric chemistry models. This is because $\mathrm{Br}_{2}$ has a very low solubility leading to a very small time of residence in small particles such as sulphate and sea salt aerosols. In this case $\mathrm{Br}_{2}$ is very rapidly released to the gas phase before Reaction (R3) can take place. Since cloud droplets and raindrops have larger radius than aerosols, the $\mathrm{Br}_{2}$ residence time in these droplets is larger. In this case, Reaction (R3) has time to take place and must be taken into account. As shown in Appendix $\mathrm{A}$, the residence time of $\mathrm{Br}_{2}$ in the cloud droplets $\left(\sim 3 \times 10^{-4} \mathrm{~s}\right)$ is nevertheless smaller than the characteristic time of Reaction (R3) $\left(9 \times 10^{-3}\right.$ s) leading to a significant release of $\mathrm{Br}_{2}$ in the gas phase from cloud droplets similarly to aerosols. On the contrary, the residence time of $\mathrm{Br}_{2}$ in the raindrops $(\sim 0.1 \mathrm{~s})$ is larger than the characteristic time of Reaction (R3) leading to a weak release of $\mathrm{Br}_{2}$ in the gas phase. For this reason, in this paper, the release of $\mathrm{Br}_{2}$ by aqueous reactions in raindrops is neglected relatively to the release by aqueous reactions in cloud droplets. For the cloud droplets, Henry's equilibrium between the gas and the aqueous phases of $\mathrm{Br}_{2}$ may be assumed and Reactions (R2) and (R3) can be then written in the condensed form:

$$
\begin{aligned}
& \mathrm{HOBr}_{\mathrm{C}}+\mathrm{Br}^{-} \rightarrow \mathrm{Br}_{2 \mathrm{~g}} \text { with the rate constant } \\
& k_{4}=k_{2}\left[\mathrm{H}^{+}\right] /\left(6.02 \times 10^{20} \times V_{\mathrm{C}}\right) \\
& \mathrm{Br}_{2 \mathrm{~g}} \rightarrow \mathrm{HOBr}_{\mathrm{C}}+\mathrm{Br}^{-} \text {with the rate constant } \\
& k_{5}=k_{3} \times \mathrm{H}_{\mathrm{Br} 2} R T V_{\mathrm{C}}
\end{aligned}
$$

where $\mathrm{HOBr}_{\mathrm{C}}$ and $\mathrm{Br}^{-}$represent the in-cloud species for $\mathrm{HOBr}$ molecules and the $\mathrm{Br}$ ions resulting from $\mathrm{HBr}$ dissolution in the aqueous phase. Note that $k_{4}$ depends on the $\mathrm{pH}$ of 


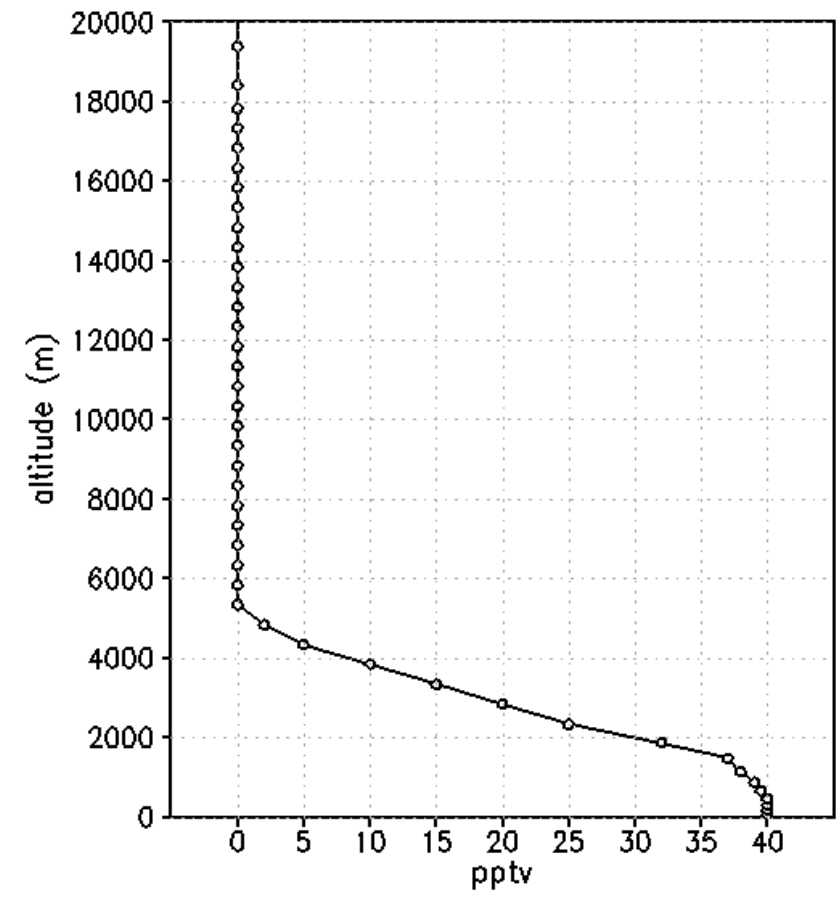

Fig. 1. Initial bromoform profile used in the BG1 and PERT1 simulations. This profile is set homogeneously horizontally over the whole domain.

the cloud droplets. The concentrations of the aqueous phase species is represented in units of molecules per $\mathrm{cm}^{3}$ of air.

For $\mathrm{HBr}$ and $\mathrm{HOBr}$ the Henry's equilibrium cannot be assumed. Therefore aqueous chemistry Eqs. (2) and (3) are solved similarly to the gaseous chemistry (Eq. 1). Equations (1), (2) and (3) are solved simultaneously with the chemical solver Rosenbrock RODAS3 (Sandu et al., 1997).

The dry deposition is taken into account for soluble species, in particular for $\mathrm{HBr}, \mathrm{HOBr}$ and soluble bromine organic species. The dry deposition velocity is computed using the surface resistance defined by Wesely (1989).

\subsection{Chemistry initialisation}

The initialisation is the same for the BG and PERT simulations. At the beginning of the simulations, $\mathrm{CO}, \mathrm{O}_{3}$ and $\mathrm{CH}_{4}$ are assumed to be uniform horizontally and fixed vertically to the averaged profiles computed by the global Chemistry Transport Model MOCAGE (Josse et al., 2004; Bousserez et al., 2007) at the grid point closest to Darwin $\left(12^{\circ} \mathrm{S}, 131^{\circ} \mathrm{W}\right)$ for the whole of November 2005. The MOCAGE simulation has a $2 \times 2^{\circ}$ horizontal resolution and uses the RACM scheme for tropospheric chemistry (Stockwell et al., 1997) and the REPROBUS scheme for stratospheric chemistry (Lefèvre et al., 1994). The chemical composition of the profile selected is typical of moderately polluted conditions. Since $\mathrm{HNO}_{3}$ is the most abundant $\mathrm{NO}_{\mathrm{y}}$ species, it is initialised with the MOCAGE mean profile of $\mathrm{NO}_{\mathrm{y}}$ and other $\mathrm{NO}_{\mathrm{y}}$ species are set to zero. Bromoform is assumed to decrease from the surface to the upper levels with the maximum mixing ratios located in the first $1 \mathrm{~km}$ (approximate depth of the boundary layer). Two background simulations, called BG1 and BG2 hereafter, are run. For BG1, an initial mixing ratio of 40 pptv of bromoform is assumed at the surface. It corresponds to the maximum values measured close to the sources by Yokouchi et al. (2005) in the Eastern Pacific. For BG2 an initial mixing ratio of $1.6 \mathrm{pptv}$ is assumed. It corresponds to the mean value of the measurements compiled in WMO 2010 (Montzka et al., 2011). It is close to those measured by Yokouchi et al. (2005) and by Brinkmann et al. (2012) in the Western Pacific. The data collected in Yokouchi et al. (2005) were mainly obtained during 2003 and therefore reasonably up to date for use in this study. Figure 1 shows the initial profile of the $\mathrm{CHBr}_{3}$ mixing ratio in the BG1 simulation. The shape of the initial profile of $\mathrm{CHBr}_{3}$ is the same in the BG2 simulation. All other bromine species are set to zero initially, including inorganic and organic bromine product gases. No emissions are assumed during the BG and PERT simulations. The simulation represents therefore the evolution of an air mass initially rich in bromoform. Note that the dry deposition is the only loss mechanism for $\mathrm{Br}_{\mathrm{y}}$ species in the $\mathrm{BG}$ simulation because this simulation corresponds to stable and cloud/rain free conditions.

\section{Results}

\subsection{The BG simulations}

The time step for the dynamics of the BG simulations is $30 \mathrm{~s}$. The maximum chemical time step is $180 \mathrm{~s}$. It is reduced, when needed, to increase the accuracy of the calculations. Photolysis rates are computed on-line every $300 \mathrm{~s}$. The BG simulation is run from 16 May, 23:00 UTC until 26 May, 23:00 UTC. This duration of 10 days corresponds approximately to the lifetime of the bromoform at the latitude and the season of the simulation. Since it is the number of bromine atoms reaching the TTL that is of interest, all mixing ratios of bromine species are weighted hereafter by the number of bromine atoms they contain and this bromine atom mixing ratio will be referred to as BrWMR. For example, the mixing ratio of $\mathrm{CHBr}_{3}$ will hereafter refer to 3 times the actual $\mathrm{CHBr}_{3}$ mixing ratio to account for the three bromine atoms in the molecule.

Figure 2 shows the evolution of the bromoform and of its product gases at the altitude of $1 \mathrm{~km}$ at the middle point of the domain in the BG1 simulation. The decrease of $\mathrm{CHBr}_{3}$ is mainly due to photolysis and to the reaction with $\mathrm{OH}$. Photolysis is more efficient than the reaction with $\mathrm{OH}$ as shown in Table 2. The computed lifetime at $1 \mathrm{~km}$ altitude is 9.1 days (Table 2). This lifetime is smaller than the global mean lifetime of bromoform which is 26 days (Montzka et al., 2011). This is due to the low ozone column prevailing at the location 


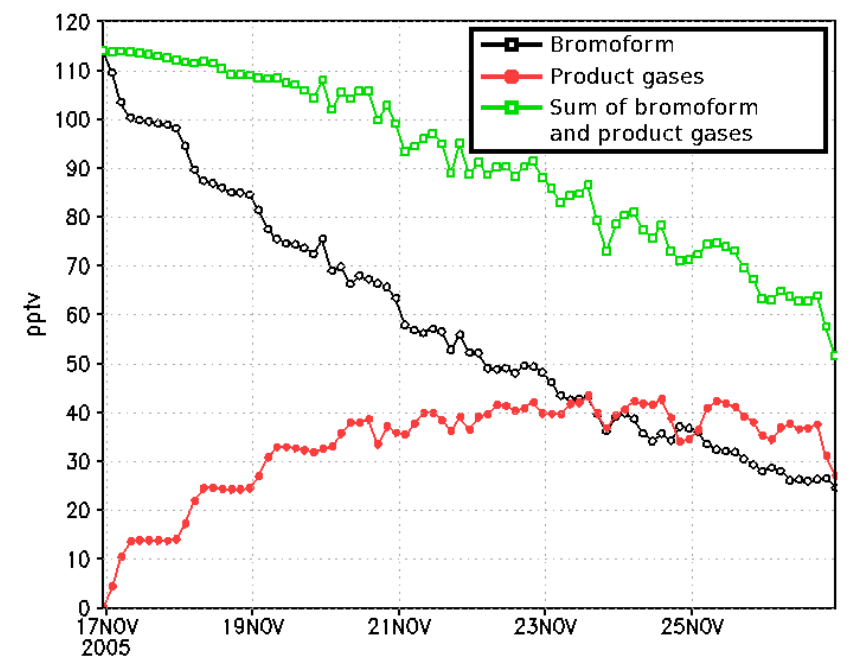

Fig. 2. Time evolution of the BrWMR for bromoform (black), in product gases (red) and in the sum (green) over the 10 days of the BG1 simulation at $1 \mathrm{~km}$ altitude $12.4^{\circ} \mathrm{S}$ and $130.9^{\circ} \mathrm{W}$ (middle point of the domain).

of the simulation and to the large concentration of $\mathrm{OH}$ (Table 2). The decrease of $\mathrm{CHBr}_{3}$ is also due to the vertical diffusion. Table 2 gives the mean values over the 10-day simulation, at $1 \mathrm{~km}$ altitude, of $\mathrm{OH}, \mathrm{HO}_{2}, \mathrm{NO}_{\mathrm{x}}$ and $\mathrm{O}_{3}$. The simulation corresponds to a low $\mathrm{NO}_{\mathrm{x}}$ regime which explains the low value of $\mathrm{O}_{3}$.

The mixing ratios of the PGs increase as the $\mathrm{CHBr}_{3}$ mixing ratio decreases (Fig. 2). The sum of the mixing ratios of both $\mathrm{CHBr}_{3}$ and the PGs decrease with time. This is mainly due to their loss by dry deposition and also to diffusion. Figure 2 also shows that the mixing ratios of bromoform and its PGs are of the same order of magnitude during the second part of the simulation.

Product gases (Fig. 3) are mainly in the form of $\mathrm{HBr}$, which is the final product of the bromoform degradation. The increase of $\mathrm{HBr}$ mixing ratios are nevertheless limited by dry deposition. After 5 days of simulation, the $\mathrm{HBr}$ mixing ratio is between 2 and 3 times larger than the organic product gases and 5 times larger than the other inorganic product gases. Among the organic product gases, the most abundant is $\mathrm{CBr}_{2} \mathrm{O}$ (maximum: 7 pptv $\mathrm{BrWMR}$ ). $\mathrm{CBr}_{3} \mathrm{OOH}$, $\mathrm{CHBr}_{2} \mathrm{OOH}$ and $\mathrm{CHBrO}$ are of the same order of magnitude (maximum $\sim 2$ pptv BrWMR) while $\mathrm{CBr}_{3} \mathrm{O}_{2}$ and $\mathrm{CHBr}_{2} \mathrm{O}_{2}$ have very low concentrations. Note that $\mathrm{CBr}_{3} \mathrm{OOH}$ and $\mathrm{CHBr}_{2} \mathrm{OOH}$ are highly soluble while $\mathrm{CBr}_{2} \mathrm{O}$ and $\mathrm{CHBrO}$ have low solubilities.

The large $\mathrm{BrWMR}$ of $\mathrm{CBr}_{2} \mathrm{O}$ compared with the BrWMR of $\mathrm{CHBrO}$ is due to its larger photolysis lifetime (Hossaini et al., 2010). It is mainly produced by the degradation of $\mathrm{CHBr}_{3}$ by $\mathrm{OH}$ while $\mathrm{CHBrO}$ is produced by photolysis of $\mathrm{CHBr}_{3}$. Thus, $\mathrm{OH}$ plays an important role in the production of the less soluble organic PGs. This is why we checked a posteriori

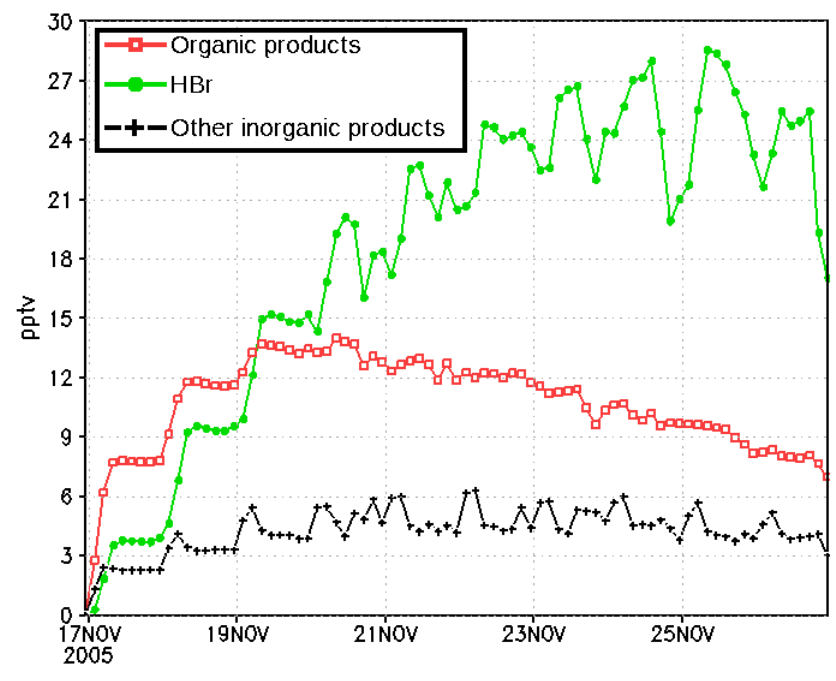

Fig. 3. Same as Fig. 2 but for $\mathrm{HBr}$ (green), for organic products $\left(\mathrm{CBr}_{3} \mathrm{OOH}+\mathrm{CHBr}_{2} \mathrm{OOH}+\mathrm{CBr}_{2} \mathrm{O}+\mathrm{CHBrO}\right)$ (red) and for other inorganic products $\left(\mathrm{Br}+\mathrm{BrO}+\mathrm{HOBr}+\mathrm{BrONO}_{2}\right)$ (black) from the BG1 simulation.

that the $\mathrm{OH}$ concentrations calculated in our simulations are realistic. For this we compared with a $\mathrm{OH}$ climatology and with available measurements in similar atmospheric conditions. Figure 4a shows the $\mathrm{OH}$ profile concentration averaged over the 10 days of the BG1 simulations in the middle of the domain from 0 to $6 \mathrm{~km}$ compared with climatological 3-D zonally and monthly averaged profiles at $-12^{\circ} \mathrm{S}$ computed by using observed $\mathrm{OH}$ precursors and sinks (Spivakovsky et al., 2000). Climatological profiles are computed for January, April, July and October. Our profile compares relatively well with the climatological profile for October, which is the closest in time to our simulation (Fig. 4a). The maximum value is approximately the same in both profiles, but the maximum is reached at a lower level in our simulation. Figure $4 \mathrm{~b}$ shows the $\mathrm{OH}$ mixing ratio from 0 to $2 \mathrm{~km}$ averaged over the 10 days of the BG1 simulation excluding night time periods. Tan et al. (2001) shows OH measurements made in the tropical Pacific during the PEM-Tropics B campaign. This campaign took place in March-April 1999. Averaged OH mixing ratio (for $\mathrm{SZA}<60^{\circ}$ ) in 4 geographical Pacific tropical regions are shown for 3 altitude ranges: $<2 \mathrm{~km}, 2-8 \mathrm{~km}$ and $>8 \mathrm{~km}$. The characteristics of the northeastern region are the closest to those which prevail during our simulations in terms of sun zenith angle and pollution. The mean value measured in the northeastern region below $2 \mathrm{~km}$ is $0.238 \mathrm{pptv}$ (Tan et al., 2001). This result cannot be strictly compared with our mean value (see Fig. $4 \mathrm{~b}$ ) in the range $0-2 \mathrm{~km}$ during the day time period $(0.227 \mathrm{pptv})$ since the sampling of the SZA of the two data sets are close but not identical. Nevertheless the $\mathrm{OH}$ mixing ratios in our simulations are consistent with the measurements. 
Table 2. Concentration and lifetime of important species for the organic bromine chemistry in the BG simulation at $1 \mathrm{~km}$.

\begin{tabular}{cccccccc}
\hline $\begin{array}{c}\mathrm{OH}^{\mathrm{a}} \\
\left(\mathrm{cm}^{-3}\right)\end{array}$ & $\begin{array}{c}\mathrm{HO}_{2}^{\mathrm{a}} \\
\left(\mathrm{cm}^{-3}\right)\end{array}$ & $\begin{array}{c}\mathrm{NO}_{\mathrm{x}}{ }^{\mathrm{a}} \\
(\mathrm{pptv})\end{array}$ & $\begin{array}{c}\mathrm{O}_{3}^{\mathrm{a}} \\
(\mathrm{ppbv})\end{array}$ & $\begin{array}{c}\mathrm{O}_{3} \text { column }^{\mathrm{a}} \\
(\mathrm{DU})\end{array}$ & $\begin{array}{c}\tau_{\mathrm{OH}}^{\mathrm{b}} \\
(\text { days })\end{array}$ & $\begin{array}{c}\tau_{J}^{\mathrm{c}} \\
(\text { days })\end{array}$ & $\begin{array}{c}\tau^{\mathrm{d}} \\
(\text { days })\end{array}$ \\
\hline $2.72 \times 10^{6}$ & $1.96 \times 10^{8}$ & 13 & 14 & 250 & 22.6 & 15.2 & 9.1 \\
\hline
\end{tabular}

${ }^{a}$ Averaged values over the 10 days of the simulation; ${ }^{b}$ Lifetime of $\mathrm{CHBr}_{3}$ relative to $\mathrm{OH} ;{ }^{\mathrm{c}}$ Lifetime of $\mathrm{CHBr}_{3}$ relative to photolysis; ${ }^{\mathrm{d}}$ Total lifetime of $\mathrm{CHBr}_{3}$.
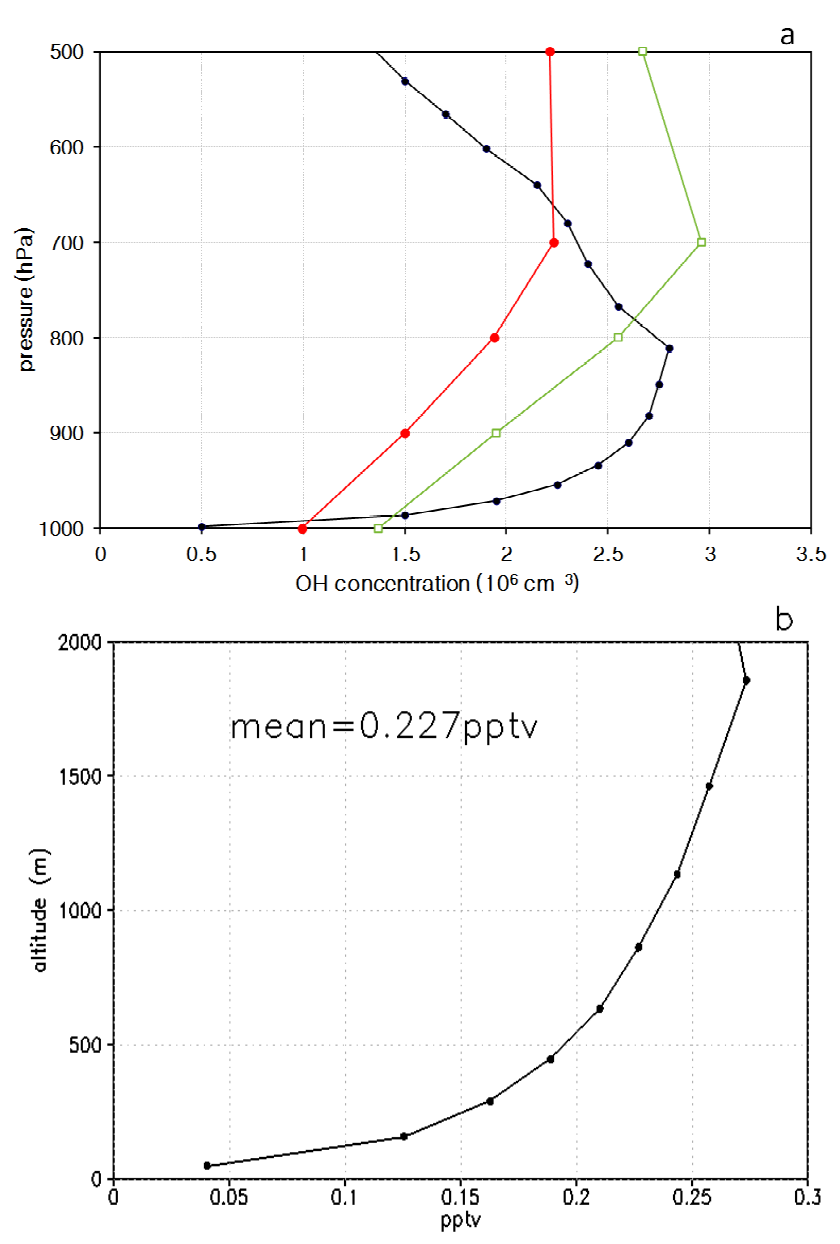

Fig. 4. (a) $\mathrm{OH}$ concentration averaged on the 10 days of the BG1 simulation (including night time periods) as a function of pressure (black), climatological 3-D-computed zonally and monthly averaged $\mathrm{OH}$ concentration on October at $-12^{\circ} \mathrm{S}$ (green) (Spivakovsky et al., 2000) and climatological 3-D-computed mean zonally averaged $\mathrm{OH}$ concentration on January, April, July and October at $-12^{\circ} \mathrm{S}$ (red) (Spivakovsky et al., 2000), (b) $\mathrm{OH}$ mixing ratio averaged on the 10 days of the BG simulation (including only day time periods) as a function of altitude. The mean value in the $0-2 \mathrm{~km}$ layer is indicated in the figure.

Throughout the BG2 simulation, we see a decrease of the bromoform and an increase of the organic and inorganic PGs similar to the BG1 simulation. The absolute values of the mixing ratios of all the species are proportional to the initial value of $\mathrm{CHBr}_{3}$ in the $\mathrm{BG} 2$ simulation compared with the BG1 simulation. Therefore, we do not discuss the BG2 simulation further since the conclusions of BG2 parallel those of BG1.

\subsection{The PERT simulations}

The two PERT simulations correspond to model runs including the development of a convective cloud initiated by temperature and moisture perturbations applied after 5 days and $6 \mathrm{~h}$ of simulation (see description in Sect. 2.1). This start time (noted $t_{0}$ ) has been chosen because the ratio of the mixing ratio of the PGs to the mixing ratio of $\mathrm{CHBr}_{3}$ is approximately equal to the mean of this ratio over the 10 days of the BG1 and BG2 simulations. In the PERT2 simulation the initial mixing ratio $\mathrm{CHBr}_{3}$ is $40 \mathrm{pptv}$. It is $1.6 \mathrm{pptv}$ in the PERT2 simulation. In these simulations the dynamical time step is $4 \mathrm{~s}$ and the maximum chemical step is $12 \mathrm{~s}$. Photolysis rates are computed every $100 \mathrm{~s}$. At $t_{0}$, the mixing ratio of bromoform is of the same order of magnitude as the mixing ratio of the product gases in the low levels (Fig. 2). Figure 5 presents vertical cross-sections in the middle of the convective cloud at different times. Twenty minutes after the starting time of the perturbation $\left(t_{0}+20 \mathrm{~min}\right)$ convection reaches $13 \mathrm{~km}$ altitude with total condensed droplets (liquid + ice), rain and liquid cloud mixing ratios up to $16 \mathrm{~g} \mathrm{~kg}^{-1}, 8 \mathrm{~g} \mathrm{~kg}^{-1}$ and $3.3 \mathrm{~g} \mathrm{~kg}^{-1}$, respectively. At $t_{0}+30$ min convection is fully developed with a maximum altitude of $\sim 17 \mathrm{~km}$, i.e. within the TTL. At this time, the maximum rain mixing ratio is $15 \mathrm{~g} \mathrm{~kg}^{-1}$ while liquid cloud mixing ratios are lower than $0.5 \mathrm{~g} \mathrm{~kg}^{-1}$. Above $6 \mathrm{~km}$, the condensed phase is only composed of ice particles with mixing ratios of up to $5 \mathrm{~g} \mathrm{~kg}^{-1}$. The rain and the liquid cloud totally disappear after $t_{0}+110 \mathrm{~min}$ while ice particles remain present at high altitude after $t_{0}+2 \mathrm{~h}$.

\subsubsection{The PERT1 simulation}

We firstly study the evolution of the $\mathrm{CHBr}_{3}$ source gas in the PERT1 simulation. It is transported rapidly upward when deep convection develops as illustrated by Fig. 6 showing the vertical cross-section of the $\mathrm{BrWMR}$ of $\mathrm{CHBr}_{3}$ at $t_{0}+30 \mathrm{~min}$. Its maximum value is $\sim 55 \mathrm{pptv}$ at $13.5 \mathrm{~km}$ altitude. The turbulent mixing of the chemical species is taken into account in the model leading to the dilution of $\mathrm{CHBr}_{3}$ during convection, mainly at the edges. Nevertheless the comparison with values close to the surface $(\sim 70 \mathrm{pptv})$ shows that a 

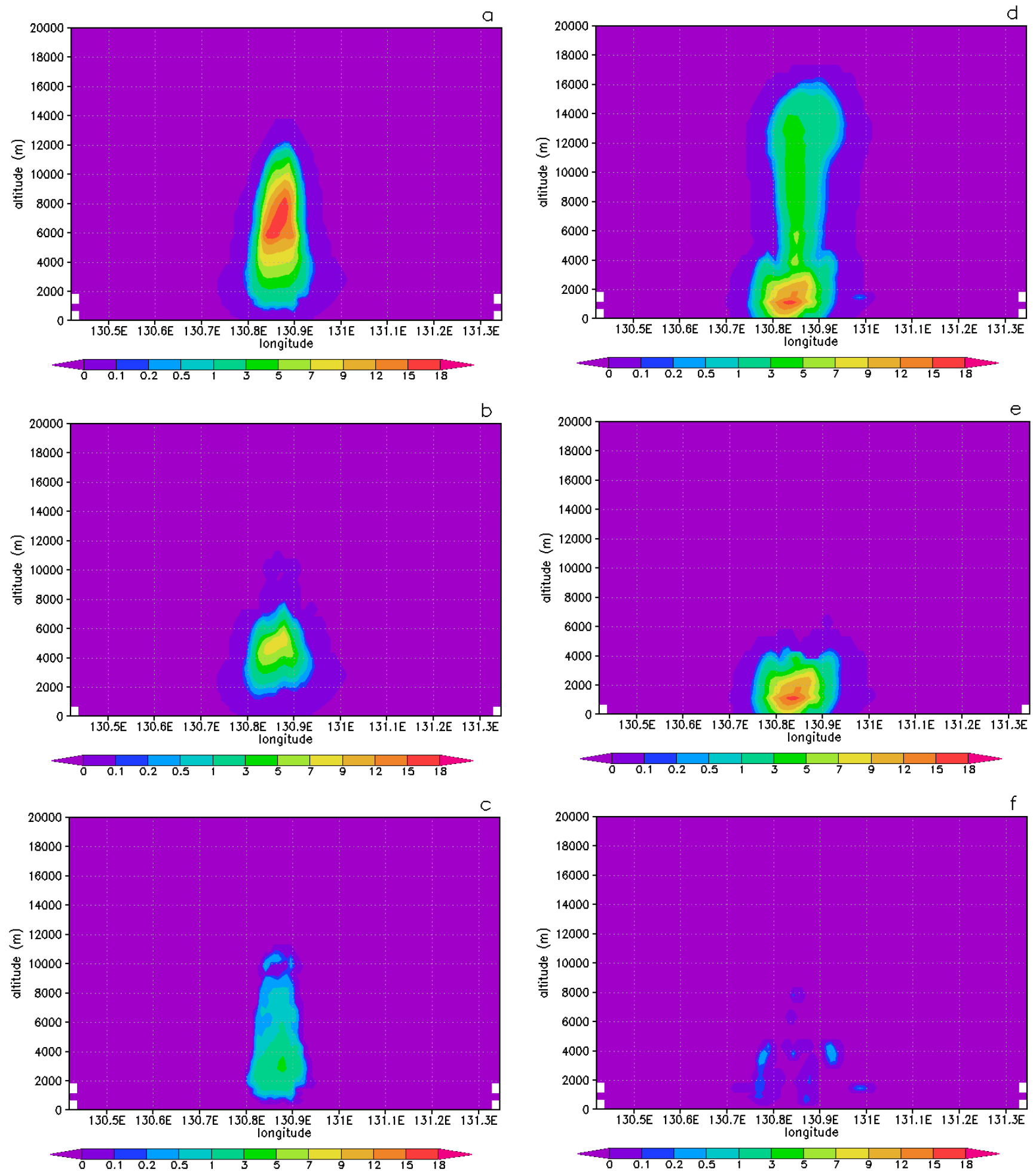

Fig. 5. Longitude-altitude cross section at $12.4^{\circ} \mathrm{S}$ of (a) the total condensed water (liquid + ice) mixing ratio $\left(\mathrm{g} \mathrm{kg}^{-1}\right)$ at $t_{0}+20 \mathrm{~min},(\mathbf{b})$ the rain mixing ratio $\left(\mathrm{g} \mathrm{kg}^{-1}\right)$ at $t_{0}+20 \mathrm{~min}$, (c) the liquid cloud mixing ratio $\left(\mathrm{g} \mathrm{kg}^{-1}\right)$ at $t_{0}+20 \mathrm{~min}$, (d) the total condensed water (liquid + ice) mixing ratio at $t_{0}+30 \mathrm{~min}$, (e) the rain mixing ratio $\left(\mathrm{g} \mathrm{kg}^{-1}\right)$ at $t_{0}+30 \mathrm{~min}$ and (f) the liquid cloud mixing ratio at $t_{0}+30 \mathrm{~min} . t_{0}$ is 5 days and $6 \mathrm{~h}$ after the beginning of the simulation. 


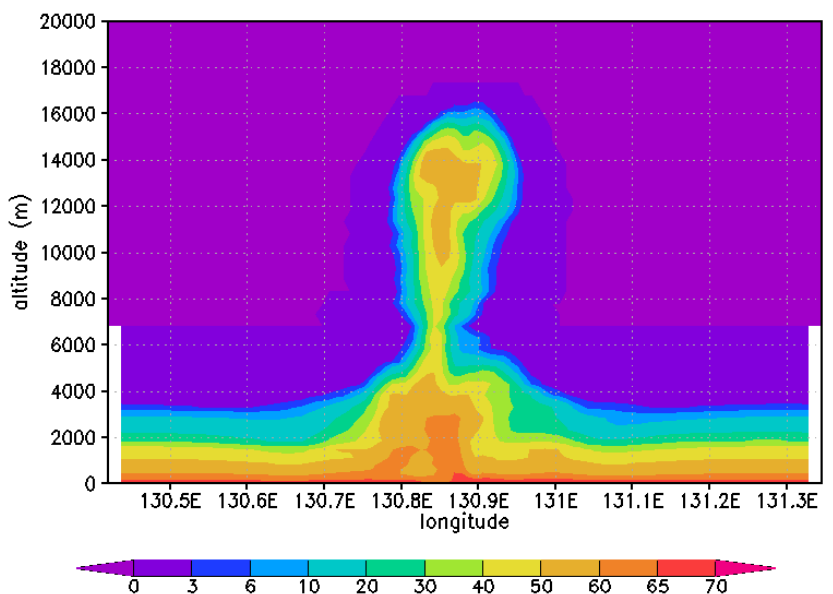

Fig. 6. Longitude altitude cross-section of the BrWMR for $\mathrm{CHBr}_{3}$ at $12.4^{\circ} \mathrm{S}$ at $t_{0}+30 \mathrm{~min}$ from the PERT1 simulation.

significant portion of the $\mathrm{CHBr}_{3}$ is transported into the upper troposphere and TTL. Because of its very low Henry's constant $\mathrm{CHBr}_{3}$ is inefficiently washed out by convective rain.

The mixing ratios of the organic product gases in the upper troposphere and TTL largely depend on their Henry's constants (see Table 1). Examples of the results for two important organic $\mathrm{PGs}\left(\mathrm{CHBr}_{2} \mathrm{OOH}\right.$ and $\left.\mathrm{CBr}_{2} \mathrm{O}\right)$ at $t_{0}+30 \mathrm{~min}$ are shown in Fig. 7. The BrWMR of $\mathrm{CHBr}_{2} \mathrm{OOH}$ is negligible in the TTL because it is washed out by rain (Fig. 7a). Among the various organic PGs, $\mathrm{CBr}_{2} \mathrm{O}$ has the highest $\mathrm{Br}$ WMR in the upper troposphere and TTL with a maximum of $\sim 7$ pptv (Fig. 7b). This is because it is largely produced by gaseous chemistry and washes out only to a small degree due to its low Henry's constant. Sensitivity tests have been made to estimate the uncertainties in the transported organic PGs in the upper troposphere due to the uncertainties in the calculated Henry's constants evaluated in Sect. 2.2. Increasing the Henry's constant for $\mathrm{CBr}_{2} \mathrm{O}$ and $\mathrm{CHBrO}$ by $44 \%$ leads to a negligible decrease in the maximum BrWMR of both species in to the upper troposphere of $0.005 \%$ and $0.015 \%$, respectively. The BrWMR of the least soluble bromine hydroperoxide transported to the upper troposphere, $\mathrm{CHBr}_{2} \mathrm{OOH}$, is increased by approximately a factor 10 when its Henry's constant is decreased by $70 \%$, reaching a maximum of $0.1 \mathrm{pptv}$. It is nevertheless still negligible with respect to the values of the $\mathrm{BrWMR}$ of $\mathrm{CBr}_{2} \mathrm{O}$ and $\mathrm{CHBrO}$ (7 and 1.8 pptv).

The analysis of the inorganic species is more complex since they undergo not only gaseous chemistry and wash out but also hydrolysis and aqueous chemistry. After cloud and rain formation, the resulting hydrolysis rapidly leads to a severe loss of $\mathrm{BrONO}_{2}$ and then to $\mathrm{HOBr}$ formation. Simultaneously, most of the $\mathrm{HOBr}$ and $\mathrm{HBr}$ is dissolved in rain and then scavenged. Figure 8 shows the vertical cross-section of $\mathrm{HBr}$ at the maximum of the convection development. Very low BrWMR of $\mathrm{HBr}$ (less than $0.1 \mathrm{pptv}$ ) are found in the upper troposphere. This justifies not taking into account the re- actions with the ice particles present in the upper troposphere in these simulations since the main reactions on ice are between inorganic bromine species and $\mathrm{HBr}$ adsorbed on the ice surfaces (Aschmann et al., 2011). Part of $\mathrm{HBr}$ and $\mathrm{HOBr}$ is also dissolved in the cloud droplets where they undergo Reaction (R4) and form $\mathrm{Br}_{2}$ in the gas phase. This gaseous $\mathrm{Br}_{2}$ rapidly forms $\mathrm{Br}, \mathrm{BrO}$ and $\mathrm{HOBr}$ in sunlit conditions. The formation efficiency for $\mathrm{Br}_{2}$ depends on the $\mathrm{pH}$ of the cloud droplets. This is illustrated in Fig. 9 showing the crosssections of $\mathrm{Br}_{\mathrm{x}}\left(\mathrm{Br}+2 \mathrm{Br}_{2}+\mathrm{BrO}+\mathrm{HOBr}\right)$ in the gas phase at $t_{0}+20 \min$ for $\mathrm{pH}=5$ and $\mathrm{pH}=4$. The $\mathrm{pH}=5$ case corresponds to standard atmospheric conditions while $\mathrm{pH}=4$ represents more polluted acidic conditions. With $\mathrm{pH}=4$ there is more gaseous $\mathrm{Br}_{\mathrm{x}}$ produced because Reaction (R4) is more efficient.

$\mathrm{Br}_{\mathrm{x}}$ is produced in smaller amounts in the middle of the convective system than at the edge of the convective system. This is firstly because $\mathrm{Br}_{2}$ is less produced in the middle of the convective system since $\mathrm{HOBr}$ and $\mathrm{HBr}$ are more rapidly washed out by rain and dissolve less in the cloud droplets. Secondly, the so-called "bromine explosion" phenomenon described in Barrie et al. (1988) on sea salt aerosols can take place in our simulations. This phenomenon can be observed at the edge of the convective system because sunlight is present. Due to the presence of sunlight, $\mathrm{Br}_{2}$ is photolysed, leading to the formation of $\mathrm{Br}, \mathrm{BrO}$ and $\mathrm{HOBr}$, which can react again with $\mathrm{HBr}$ in the aqueous phase. This leads to a continuous loss of $\mathrm{HBr}$ and to a continuous production of $\mathrm{Br}_{\mathrm{x}}$. On the contrary, thick clouds in the middle of the convective system strongly reduce radiation and thus the photolysis of $\mathrm{Br}_{2}$, which prevents the bromine explosion from taking place. Figure 10 shows the cross-section of $\mathrm{Br}_{\mathrm{x}}$ at the mature stage of the convective cloud $\left(t_{0}+30 \mathrm{~min}\right)$ for both $\mathrm{pH}=5$ and $\mathrm{pH}=4$. At this time, $\mathrm{Br}_{\mathrm{x}}$ has reached the TTL with higher $\mathrm{BrWMR}$ for $\mathrm{pH}=4(\max \sim 8 \mathrm{pptv})$ than for $\mathrm{pH}=5$ (max $\sim 3 \mathrm{pptv}$ ), similarly to $t_{0}+20 \mathrm{~min}$. The largest BrWMRs remain in the low and mid troposphere because the larger $\mathrm{Br}_{\mathrm{x}}$ mixing ratios are formed at the edges of the convective system where vertical transport is weaker than in the middle of the convective system.

Figure 11 shows the vertical cross-sections of $\mathrm{CHBr}_{3}$ and of the total PGs in the PERT1 simulation compared with the BG1 simulation at the end of the convective event $\left(t_{0}+110 \mathrm{~min}\right)$. The impact of convection on the chemical composition of the lower troposphere below $2 \mathrm{~km}$ altitude is relatively small. It is more important for the PGs because of the wash out of the soluble species. $\mathrm{CHBr}_{3}$ and PGs which have been lifted by the vertical winds in the convective tower remain in the upper troposphere at the end of the convective event. $\mathrm{CHBr}_{3}$ and PGs BrWMR maxima are 40 and 7 pptv, respectively, at $\sim 12 \mathrm{~km}$ altitude (see Fig. $11 \mathrm{~b}$ and d). They are lower than at $t_{0}+30 \mathrm{~min}$, the time at the maximum point of the convective development. The vertically layered structure in the distributions of $\mathrm{CHBr}_{3}$ and PGs visible in Fig. 11 and the other vertical cross sections we present results 

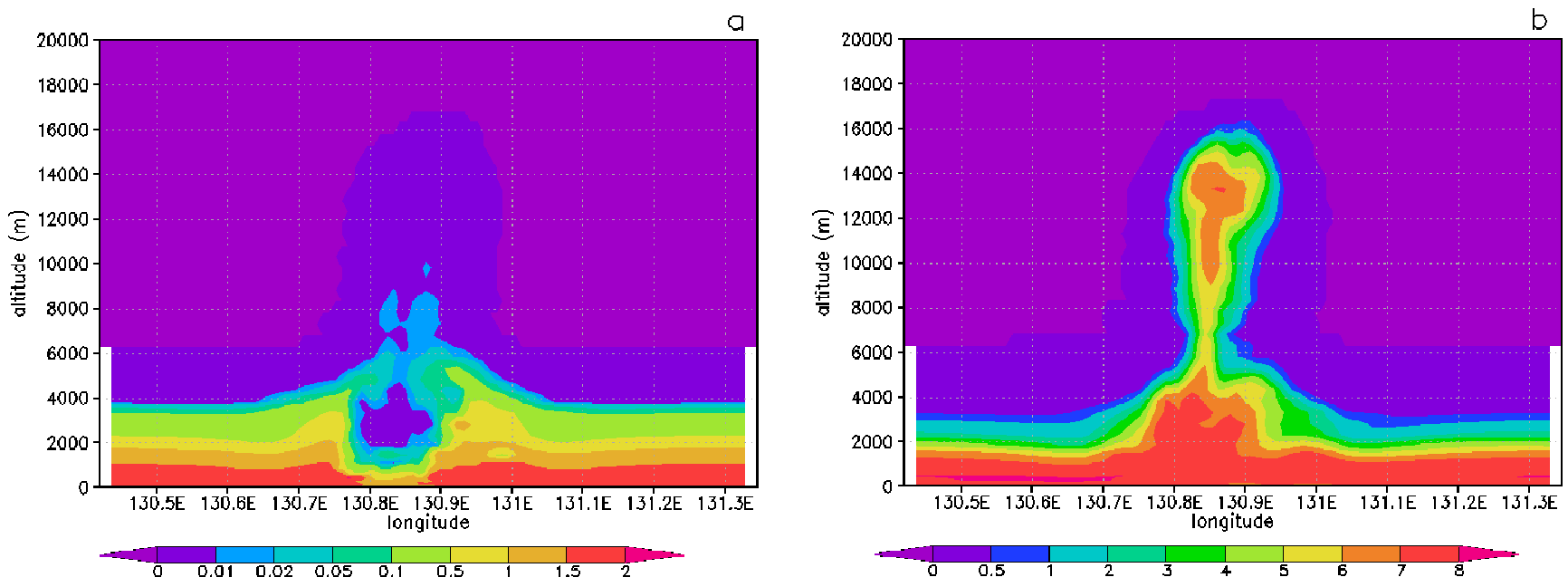

Fig. 7. Longitude-altitude cross-section at $12.4^{\circ} \mathrm{S}$ at $t_{0}+30 \mathrm{~min}$ of the $\mathrm{BrWMR}$ for (a) $\mathrm{CHBr}_{2} \mathrm{OOH}$ and (b) $\mathrm{CBr}_{2} \mathrm{O}$ from the PERT1 simulation.

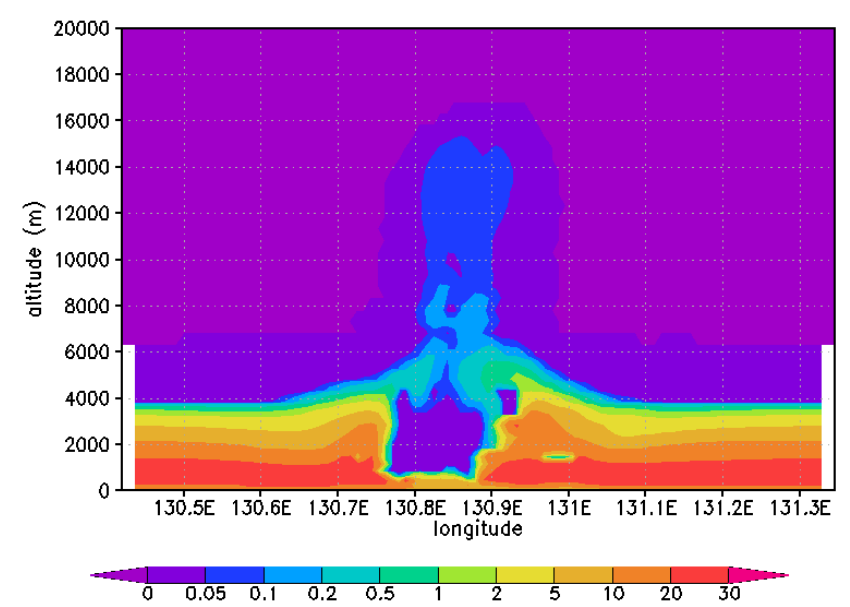

Fig. 8. Longitude-altitude cross section at $12.4^{\circ} \mathrm{S}$ at $t_{0}+30 \mathrm{~min}$ of $\mathrm{HBr}$ in pptv from the PERT1 simulation.

entirely from dynamical effects whereby there are variations in the vertical velocity within the convective column with altitude.

To analyse in more detail the final effects of the convective event we plotted in Fig. 12 the horizontally averaged BrWMR profiles of organic $\mathrm{PGs}\left(\mathrm{CBr}_{2} \mathrm{O}\right.$, CHBrO and $\left.\mathrm{CHBr}_{2} \mathrm{OOH}+\mathrm{CBr}_{3} \mathrm{OOH}\right)$ and inorganic $\mathrm{PGs}(\mathrm{Br}+\mathrm{BrO}$, $\mathrm{HOBr}$ and $\mathrm{HBr}$ ) transported to the upper troposphere at the end of the convective event $\left(t_{0}+110 \mathrm{mn}\right)$ in the case of cloud $\mathrm{pH}=5$. Profiles are shown in the range $6-20 \mathrm{~km}$. In this altitude range the species are exclusively those which have been lifted by the convective system. $\mathrm{CBr}_{2} \mathrm{O}$ is the main organic PGs transported due to its large production in the lower troposphere and its low solubility. $\mathrm{CHBr}_{2} \mathrm{OOH}$ and $\mathrm{CBr}_{3} \mathrm{OOH}$ BrWMRs are low because of their high solubility. $\mathrm{Br}+\mathrm{BrO}$ BrWMRs dominate the inorganic bromine species. They are produced by the photolysis of $\mathrm{Br}_{2}$. The $\mathrm{HBr} \mathrm{BrWMR}$ is low because of its high solubility leading to efficient scavenging. Figure 13 shows the total inorganic PGs, the total organic PGs, the total PGs and $\mathrm{CHBr}_{3}$ BrWMRs transported in the upper troposphere at the end of the convective event. Figure 13a and $\mathrm{c}$ is, respectively, for the simulations with cloud $\mathrm{pH}=5$ and with cloud $\mathrm{pH}=4$, in the altitude range $6-20 \mathrm{~km}$. Note that the mixing ratios are relatively low in Fig. 13 compared to the peak values shown in Fig. 11 because of the horizontal averaging used in Fig. 13. Thus the relative abundances shown in this figure are more important than the absolute values. After the convective event the species are located in several layers with a maximum at $12 \mathrm{~km}$. At this altitude, $0.2 \mathrm{pptv}, 0.6 \mathrm{pptv}$ and $3.7 \mathrm{pptv}$ of the inorganic PGs, organic PGs and $\mathrm{CHBr}_{3}$, respectively, are on average transported to this altitude for a cloud $\mathrm{pH}=5$. The contributions to the total amount of bromine atoms are $4.5 \%$ from the inorganic PG, $13.3 \%$ from the organic PGs and $82.2 \%$ from $\mathrm{CHBr}_{3}$. For cloud $\mathrm{pH}=4,0.45 \mathrm{pptv}$ of the inorganic PGs are transported. Because the cloud $\mathrm{pH}$ only impacts the inorganic chemistry, the same BrWMRs are computed for the organic PGs and $\mathrm{CHBr}_{3}$ as for the cloud $\mathrm{pH}=5$ case. Of the total upper atmosphere bromine atom loading, $9.5 \%$ is in the form of inorganic PGs, $12.5 \%$ are present as organic PGs and $78 \%$ as $\mathrm{CHBr}_{3}$. Figure 13b and d shows the same results as in Fig. 13a and $\mathrm{c}$ but in the TTL altitude range. In absolute values, the BrWMR present as inorganic PGs, organic PGs and $\mathrm{CHBr}_{3}$ are, respectively, $0.025 \mathrm{pptv}, 0.1 \mathrm{pptv}$ and $0.6 \mathrm{pptv}$, which corresponds to $3.5 \%, 13.8 \%$ and $82.7 \%$ relatively to the total bromine atom abundance for cloud $\mathrm{pH}=5$. For cloud $\mathrm{pH}=4,0.05 \mathrm{pptv}$ BrWMR are present as inorganic PGs, and, relative to the total bromine atom loading, this represents $6.6 \%$. Organic PGs represent $13.3 \%$ and $\mathrm{CHBr}_{3}$ represents $80 \%$ of the total bromine atoms abundance. 

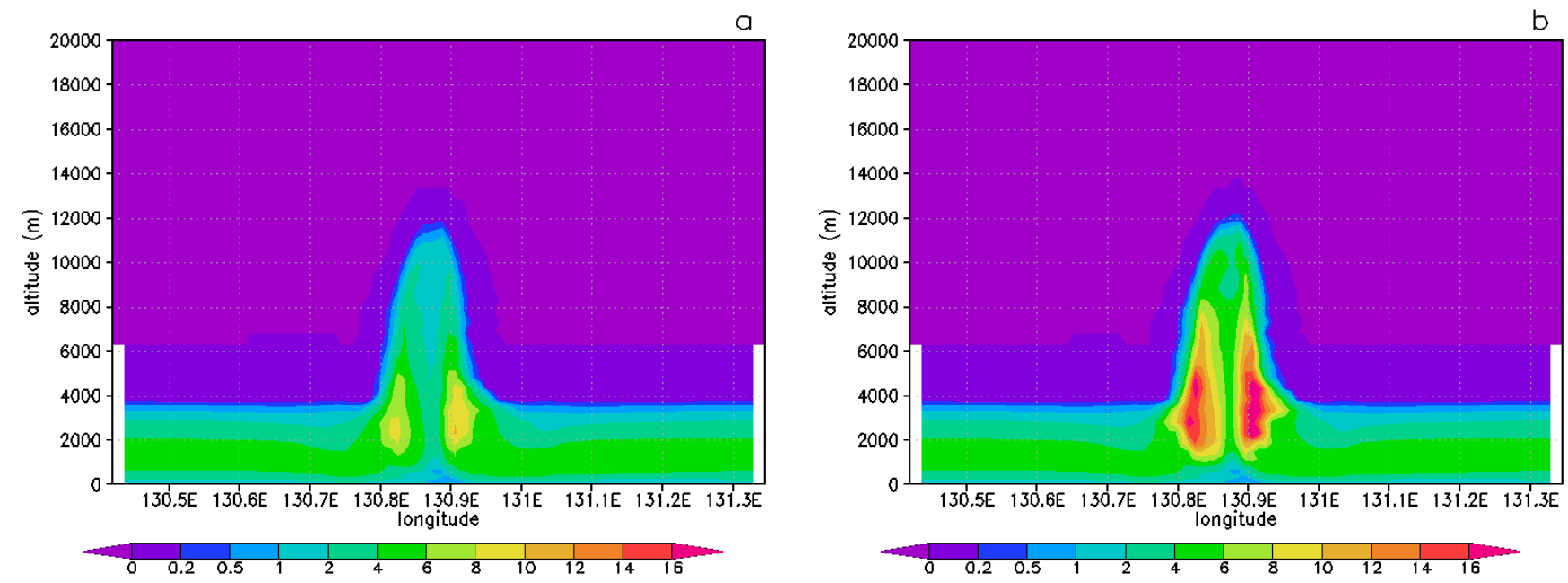

Fig. 9. Longitude-altitude cross section at $12.4^{\circ} \mathrm{S}$ at $t_{0}+20$ min from the $\mathrm{PERT} 1$ simulation of $\mathrm{Br}_{\mathrm{x}}=\mathrm{Br}+\mathrm{BrO}+2 \cdot \mathrm{Br} 2+\mathrm{HOBr}$ in pptv for (a) cloud $\mathrm{pH}=5$ and (b) cloud $\mathrm{pH}=4$.
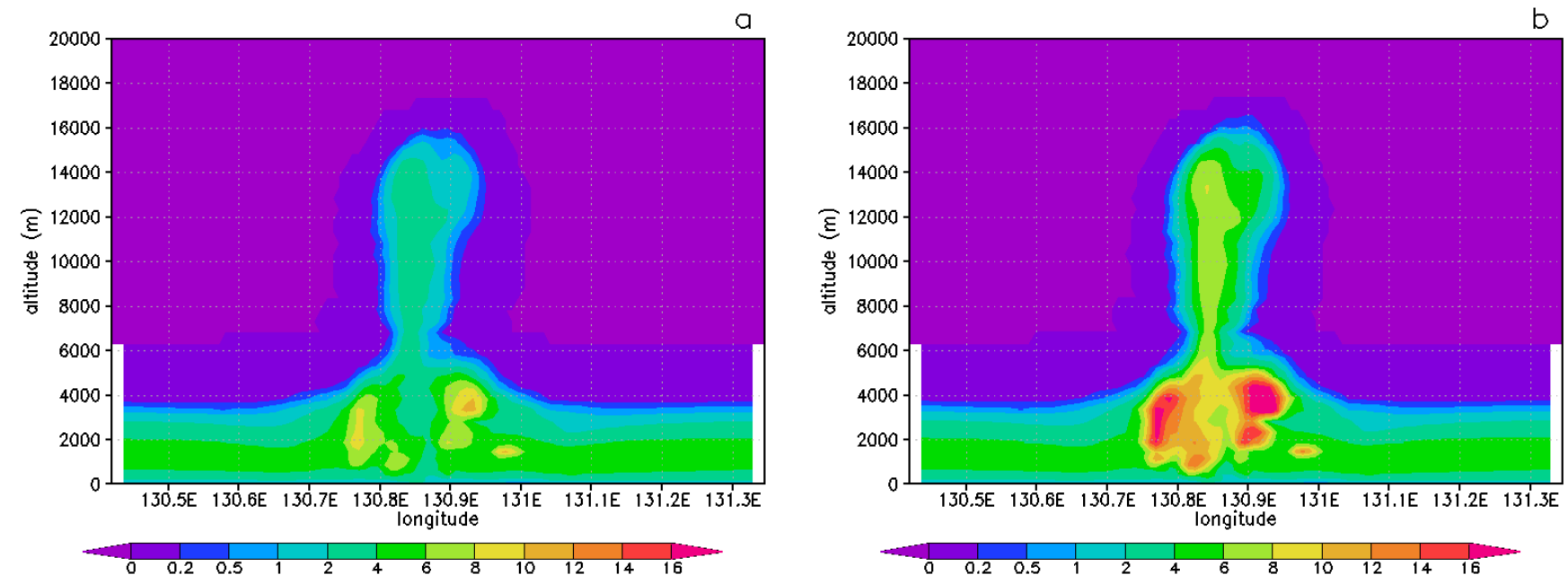

Fig. 10. Same as Fig. 9 but for $t_{0}+30 \mathrm{~min}$.

These results indicate that inorganic PGs are not fully scavenged in the convective event. The amount of inorganic PGs transported into the TTL depends on the cloud $\mathrm{pH}$. We show that convection efficiently transports organic PGs, which are, for the more abundant of them, not very soluble. In the case of large concentrations of chlorine atoms, the degradation of $\mathrm{CHBr}_{3}$ would lead to a larger production of $\mathrm{CBr}_{2} \mathrm{O}$ since the role of $\mathrm{Cl}$ is the same as $\mathrm{OH}$. This would increase the organic PGs BrWMR present in the TTL during the convective event. In the case of high sunlight conditions, as in our simulations, the BrWMR present in the upper troposphere and in the TTL due to organic PGs is non-negligible compared with bromine atom present as $\mathrm{CHBr}_{3}$.

The partitioning between $\mathrm{CHBr}_{3}$ and organic PGs is different from the results presented in Hossaini et al. (2010). From their Figs. 7 and 9, it is possible to calculate that ap- proximately $2 \%$ of bromine atoms are present as organic PGs $\left(2 \cdot \mathrm{CBr}_{2} \mathrm{O}+\mathrm{CHBrO}\right)$ compared with the total abundance of bromine atoms present at $100 \mathrm{hPa}(\sim 16 \mathrm{~km})$ at tropical latitudes. We found more than $13 \%$ of bromine atoms present as PGs in our simulations. In our study we focus on the bromine budget above a convective system. The partition between the organic PGs and $\mathrm{CHBr}_{3}$ observed in the TTL is therefore mostly representative of the chemistry in the lower troposphere since the non soluble species are rapidly transported from the lower troposphere to the TTL. In Hossaini et al. (2010), the partition between organic PGs and $\mathrm{CHBr}_{3}$ results not only from convective transport from the lower troposphere but also from the chemical processing in the TTL. In this layer the $\mathrm{OH}$ concentration is lower than in the lower troposphere. $\mathrm{CBr}_{2} \mathrm{O}$ is therefore produced in a much lower amount in the TTL than in the lower troposphere. This leads 

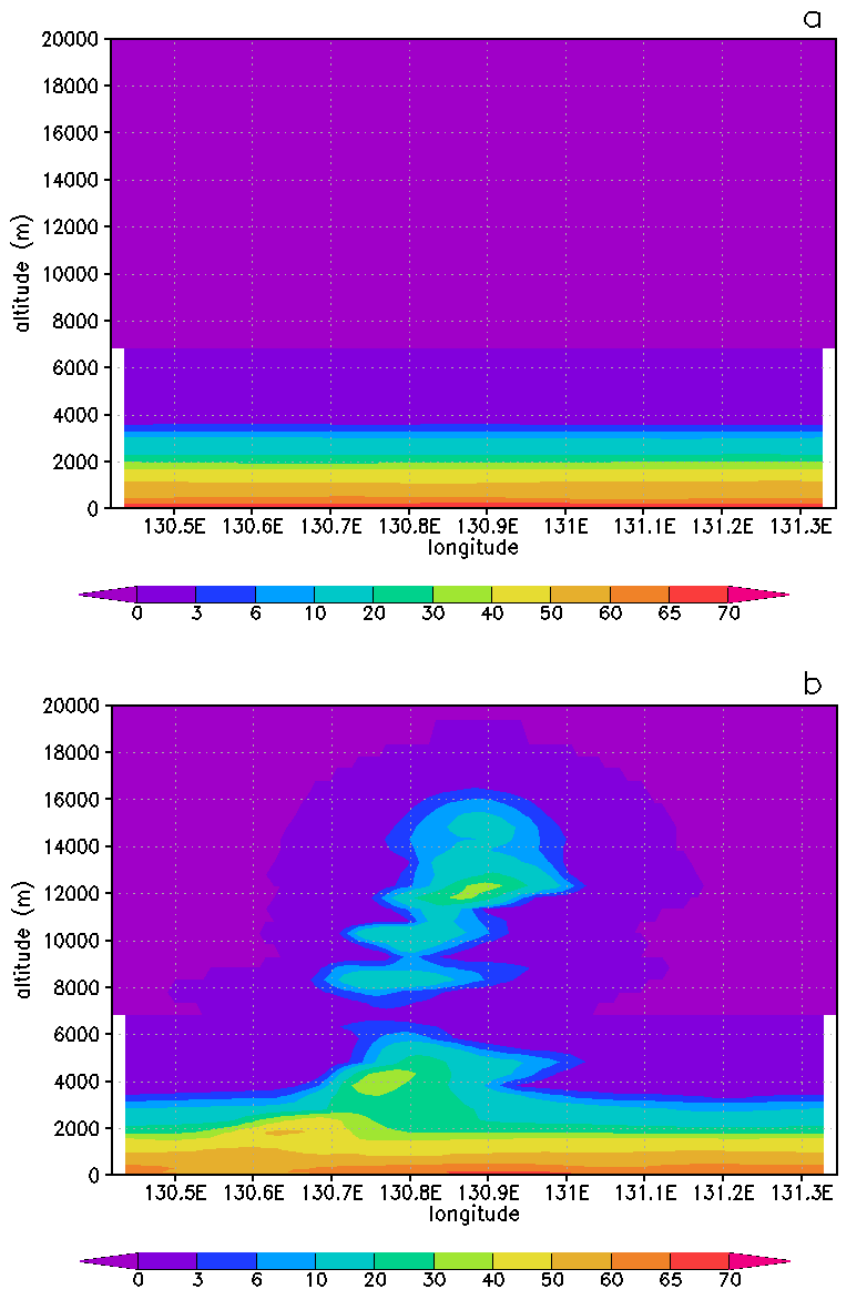
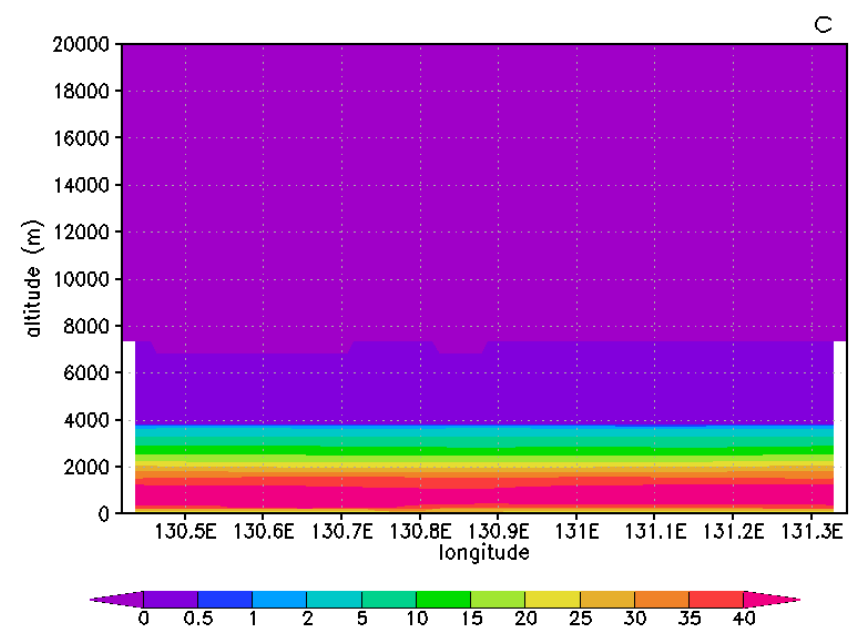

d

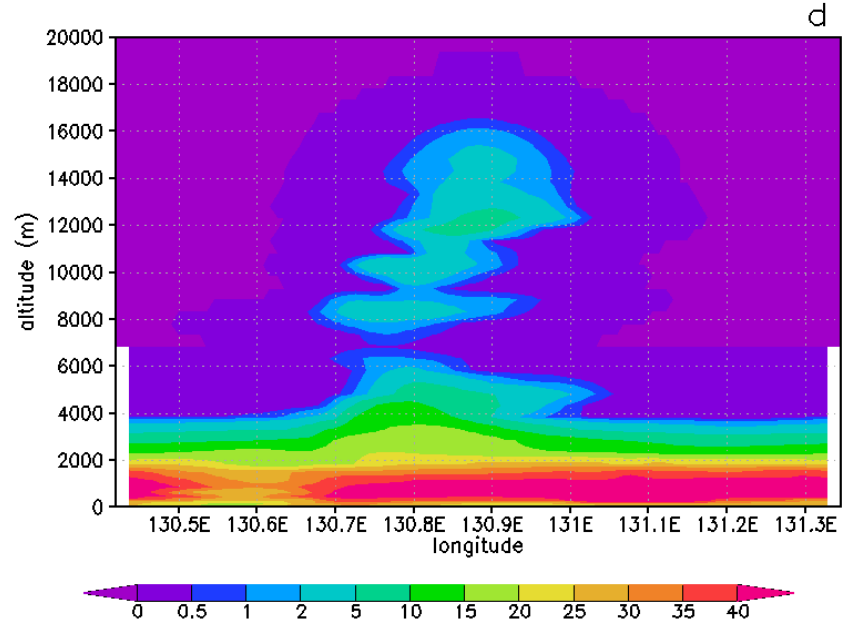

Fig. 11. Longitude-altitude cross section at $12.4^{\circ} \mathrm{S}$ of $\mathrm{BrWMR}$ for cloud $\mathrm{pH}=5$ in at $t_{0}+110 \mathrm{~min}$ in (a) $\mathrm{CHBr}_{3}$ in the $\mathrm{BG} 1$ simulation, (b) $\mathrm{CHBr}_{3}$ in the PERT1 simulation, (c) total PGs in the BG1 simulation, (d) total PGs in the PERT1 simulation.

to a shorter mean lifetime for all organic PGs in the TTL. Thus the impact of the chemistry in the TTL is to reduce the ratio of bromine atoms present as organic PGs to those present as $\mathrm{CHBr}_{3}$. This is partly why our simulations, that only take into account the convective effect, give a higher ratio. It is also partly related to the fact that the results shown in Hossaini et al. (2010) in Fig. 9 are tropical annual and zonal mean profiles while our calculations are made for high sunlight conditions and therefore have higher $\mathrm{OH}$ concentrations as shown in Fig. 4a.

\subsubsection{The role of chlorine chemistry in the aqueous phase}

Taking into account chlorine species in the aqueous phase leads to much more complex chemistry with the possible formation of $\mathrm{BrCl}$ by the reactions:

$\mathrm{HOCl}_{\mathrm{aq}}+\mathrm{Br}^{-}+\mathrm{H}^{+} \rightarrow \mathrm{BrCl}+\mathrm{H}_{2} \mathrm{O}$
$\mathrm{HOBr}_{\mathrm{aq}}+\mathrm{Cl}^{-}+\mathrm{H}^{+} \rightarrow \mathrm{BrCl}+\mathrm{H}_{2} \mathrm{O}$

In the aqueous phase $\mathrm{BrCl}$ can react with $\mathrm{H}_{2} \mathrm{O}, \mathrm{Br}^{-}$and $\mathrm{Cl}^{-}$ (Wang et al., 1994)

$$
\begin{aligned}
& \mathrm{BrCl}+\mathrm{H}_{2} \mathrm{O} \rightarrow \mathrm{HOBr}_{\mathrm{aq}}+\mathrm{Cl}^{-}+\mathrm{H}^{+} \\
& \mathrm{BrCl}+\mathrm{Br}^{-} \leftrightarrow \mathrm{Br}_{2} \mathrm{Cl}^{-} \\
& \mathrm{BrCl}+\mathrm{Cl}^{-} \leftrightarrow \mathrm{BrCl}_{2}^{-}
\end{aligned}
$$

$\mathrm{Br}_{2}$ can react with $\mathrm{Cl}^{-}$(Wang et al., 1994)

$$
\mathrm{Br}_{2}+\mathrm{Cl}^{-} \leftrightarrow \mathrm{Br}_{2} \mathrm{Cl}^{-}
$$

- $k_{6}=1.3 \times 10^{6} \mathrm{~mol}^{-2} \mathrm{l}^{2} \mathrm{~s}^{-1} \quad$ (Kumar and Margerum, 1987).

- $k_{7}>5.6 \times 10^{9} \mathrm{~mol}^{-2} \mathrm{l}^{2} \mathrm{~s}^{-1}$ (Wang et al., 1994; Fickert et al., 1999)

$-k_{8}>1 \times 10^{5} \mathrm{~s}^{-1}$ (Wang et al., 1994; Fickert et al., 1999) 

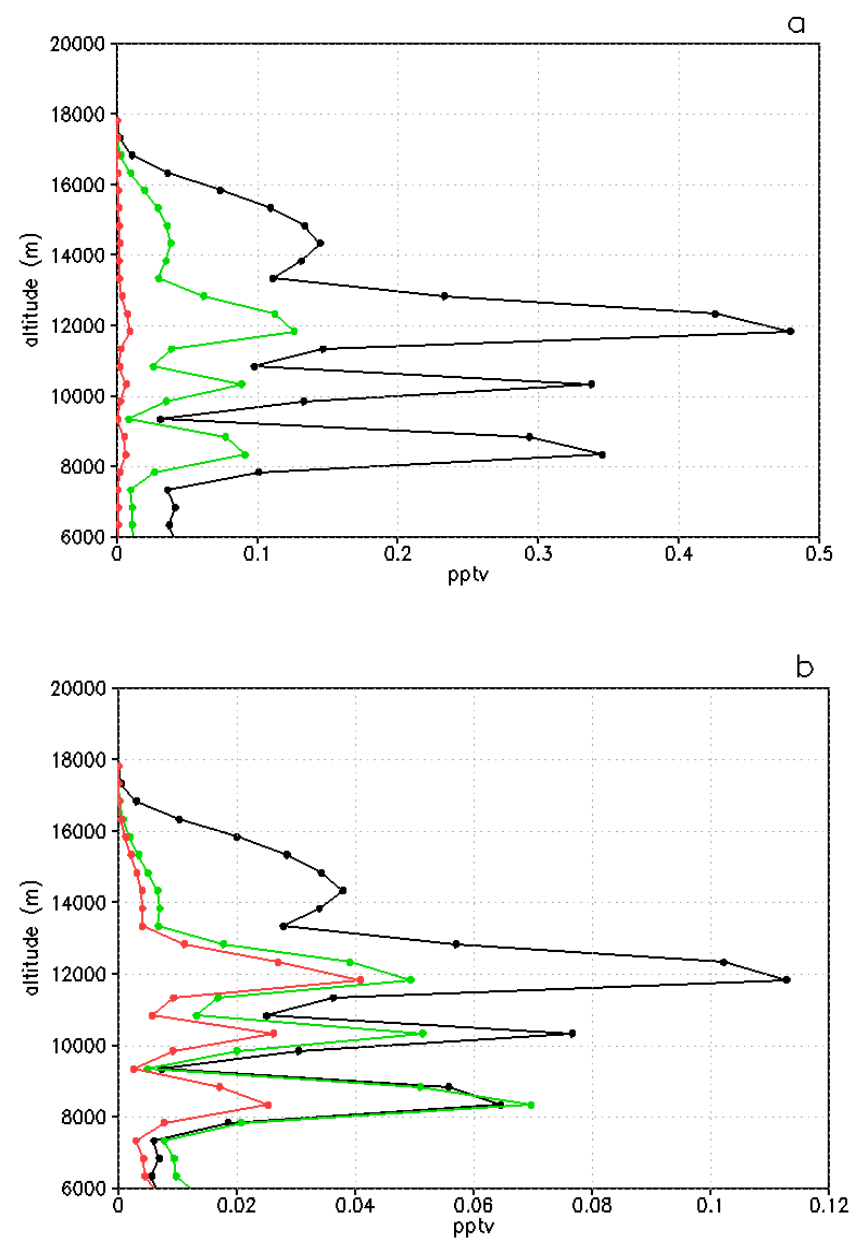

Fig. 12. Mean profiles in the altitude range $6-20 \mathrm{~km}$ at the end of the convective event $\left(t_{0}+110 \mathrm{~min}\right)$ in the PERT1 simulation of (a) $\mathrm{Br}$ WMR for the organic species, $\mathrm{CBr}_{2} \mathrm{O}$ (black), $\mathrm{CHBrO}$ (green) and $\mathrm{CHBr}_{2} \mathrm{OOH}+\mathrm{CBr}_{3} \mathrm{OOH}$ (red) averaged on the horizontal (b) same for inorganic $\mathrm{PGs}, \mathrm{Br}+\mathrm{BrO}$ (black), $\mathrm{HOBr}$ (green) and $\mathrm{HBr}$ (red) for cloud $\mathrm{pH}=5$.

- $k_{9}>1 \times 10^{8} \mathrm{~mol}^{-1} 1 \mathrm{~s}^{-1}$ (Wang et al., 1994) for the forward Reactions (R9), (R10) and (R11) are very fast reactions for which equilibrium constants are (Wang et al, 1994): $K_{9}=1.8 \times 10^{4} \mathrm{~mol}^{-1} 1 ; K_{10}=6 \mathrm{~mol}^{-1} 1$; $K_{11}=1.3 \mathrm{~mol}^{-1} 1$

Chloride ion concentrations in rain precipitation have been measured to be in between $10^{-6} \mathrm{moll}^{-1}$ and $5 \times 10^{-4} \mathrm{~mol}^{-1}$ (Graedel and Keene, 1995). The large concentrations are mainly observed above the ocean because of the wash out of sea salt aerosols by clouds and precipitation.

Using Fickert et al. (1999), Reaction (R9) followed by the inverse of Reaction (R11) leads to a rapid conversion of $\mathrm{BrCl}$ into $\mathrm{Br}_{2}$ if the $\mathrm{Br}^{-}$concentration is larger than $10^{-4}$ times the $\mathrm{Cl}^{-}$concentration. This is verified in our case study. However, this rapid conversion is possible only if the first order rate constant of Reaction (R9) $\left(k_{9} \cdot\left[\mathrm{Br}^{-}\right]\right)$is larger that the rate constant for diffusion of $\mathrm{BrCl}$ out of the cloud droplets (approximately $2 \times 10^{3} \mathrm{~s}^{-1}$ ). Since only a minimum value for $k_{9}$ is known $\left(1 \times 10^{8} \mathrm{~mol}^{-1} 1 \mathrm{~s}^{-1}\right)$, and that the $\mathrm{Br}^{-}$concentration is low (approximately $10^{-7} \mathrm{~mol}^{-1} \mathrm{l}$ ), this leads to a minimum value for $k_{9} \cdot\left[\mathrm{Br}^{-}\right]=10 \mathrm{~s}^{-1}$, which is lower than the diffusion rate of $\mathrm{BrCl}$ out of the droplet. With the present knowledge it is not possible to therefore know if this conversion is efficient in our case study. We assume in this paper that this conversion is not efficient.

We also assume that the Reaction (R6) has a small impact on the bromine chemistry. We justify this last assumption since, firstly, the rate constant $k_{6}$ is smaller by approximately a factor of $10^{4}$ than the rate constants for Reactions (R2) and (R7), and, secondly, the $\mathrm{HOCl}$ gas concentration is typically lower than $100-150$ pptv in the lower atmosphere (Graedel and Keene, 1995) while $\mathrm{HOBr}$ is on the order of $1 \mathrm{pptv}$ in our simulations. The loss rate of $\mathrm{Br}^{-}$via Reaction (R2), which is $k_{2}\left[\mathrm{H}^{+}\right][\mathrm{HOBr}]$, is therefore much larger than its loss rate via Reaction (R6), which is $k_{6}\left[\mathrm{H}^{+}\right][\mathrm{HOCl}]$.

The chemistry of $\mathrm{Br}_{2}$ and $\mathrm{BrCl}$ in the cloud droplet can be therefore treated independently by Reactions (R2), (R3) for $\mathrm{Br}_{2}$ and (R7) and (R8) for $\mathrm{BrCl}$. In the case of $\mathrm{BrCl}$ the hydrolysis is a very fast (Reaction R8, $k_{8}>10^{5} \mathrm{~s}^{-1}$ )). The diffusion rate of $\mathrm{BrCl}$ out of the cloud droplet (approximately $2 \times 10^{3} \mathrm{~s}^{-1}$ ) is therefore smaller than the rate constant of hydrolysis. This leads to a reduced production of $\mathrm{BrCl}$ in the gas phase. In the case of large concentrations of $\mathrm{Cl}^{-}$in the cloud droplet, the production of $\mathrm{BrCl}$ can be nevertheless of the same order of magnitude as the production of $\mathrm{Br}_{2}$. To test the impact of the production of $\mathrm{BrCl}$ on the transport of $\mathrm{Br}_{\mathrm{x}}$ species in the convective system, the PERT1 simulation has been re-run including the following reactions in the set of photochemical reactions:

$$
\begin{aligned}
& \mathrm{HOBr}_{\mathrm{C}}+\mathrm{Cl}^{-} \rightarrow \mathrm{BrCl}_{\mathrm{g}} \\
& \mathrm{BrCl}_{\mathrm{g}} \rightarrow \mathrm{HOBr}_{\mathrm{C}}+\mathrm{Cl}^{-}
\end{aligned}
$$

The rate constants for these reactions can be derived from relation (A6) in Appendix A assuming that the behaviour of $\mathrm{BrCl}$ in the cloud droplet is the same as the behaviour of $\mathrm{Br}_{2}$ in the rain droplets (i.e. the characteristic time for hydrolysis is larger than the residence time of the species in the droplets). If $\mathrm{Cl}^{-}$is in $\mathrm{moll}^{-1}$,

$k_{12}=k_{7}\left[\mathrm{H}^{+}\right] \times\left(k_{\mathrm{BrClC}} /\left(k_{8} \times \mathrm{H}_{\mathrm{BrCl}} R T\right)\right)$

where $k_{\mathrm{BrClC}}$ is the mass transfer coefficient defined in Sect. 2.2 and $H_{\mathrm{BrCl}}$ is the effective Henry's law constant for $\mathrm{BrCl}$ (Table 1).

$k_{13}=k_{\mathrm{BrClC}} V_{\mathrm{C}}$

The photolysis reaction of $\mathrm{BrCl}$ in the gas phase is also included in the set of reactions.

$\mathrm{BrCl}_{\mathrm{g}} \rightarrow \mathrm{Br}_{\mathrm{g}}+\left(\mathrm{Cl}_{\mathrm{g}}\right)$ 

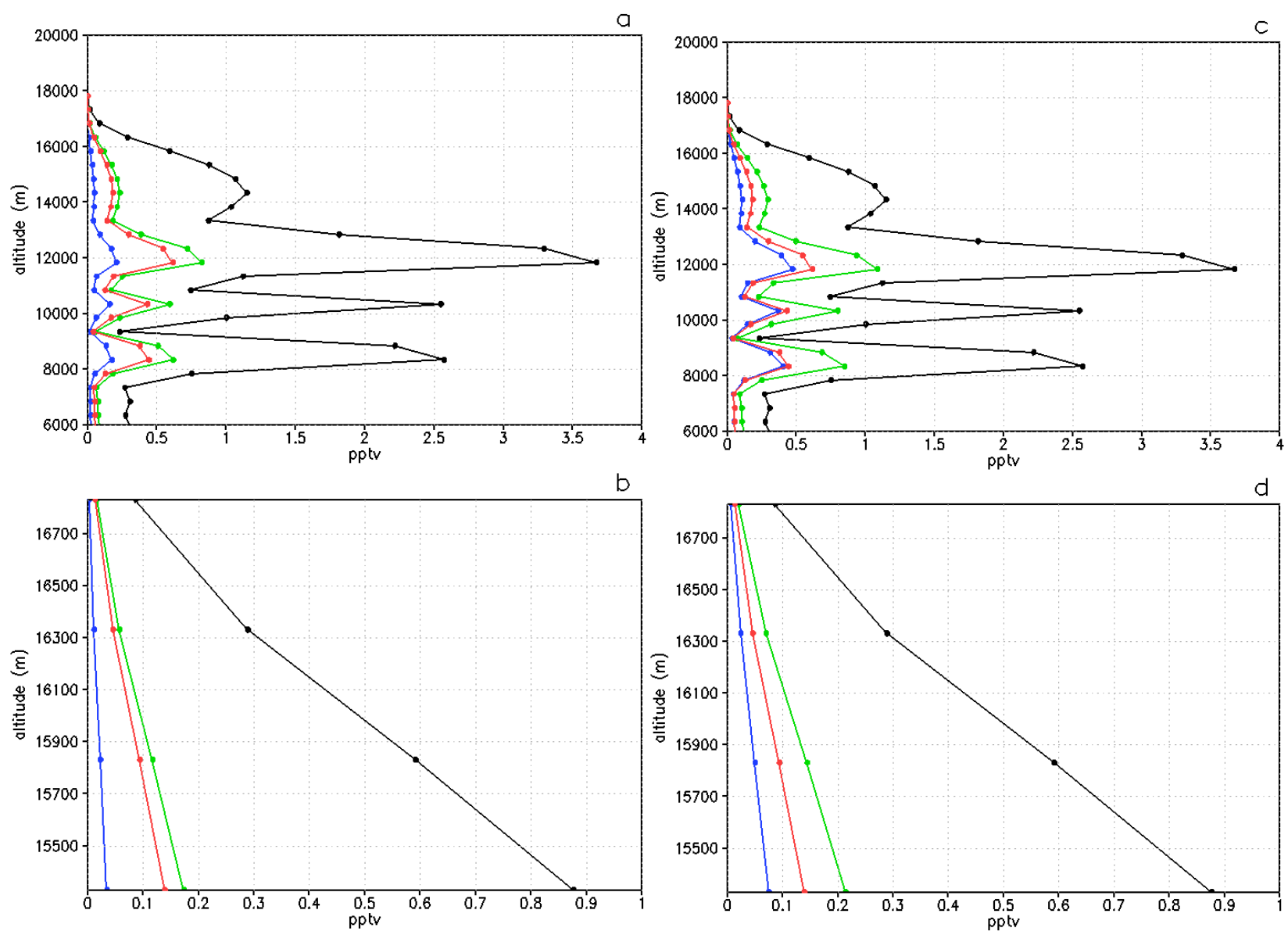

Fig. 13. Mean profiles at the end of the convective event $\left(t_{0}+110 \mathrm{~min}\right)$ of BrWMR for inorganic PGs(blue), organic PGs (red), total PGs (green) and $\mathrm{CHBr}_{3}$ (black) averaged horizontally in the PERT1 simulation for (a) cloud $\mathrm{pH}=5$, in the altitude range 6-20 km, (b) cloud $\mathrm{pH}=5$ in the TTL (c) cloud $\mathrm{pH}=4$, in the altitude range $6-20 \mathrm{~km}$, (d) cloud $\mathrm{pH}=4$, in the TTL.

We assume the maximum chloride ion concentration is $\left[\mathrm{Cl}^{-}\right]=5 \times 10^{-4} \mathrm{moll}^{-1}$. The cloud $\mathrm{pH}$ is assumed to be 5 .

Figure $14 \mathrm{a}$ shows the cross-sections of $\mathrm{Br}_{\mathrm{x}}$ $\left(\mathrm{Br}+\mathrm{BrO}+\mathrm{HOBr}+2 \mathrm{Br}_{2}\right)$ in the gas phase at $t_{0}+30 \mathrm{~min}$ when Reactions (R12), (R13) and (R14) are not taken into account. Figure $14 \mathrm{~b}$ shows the cross section of $\mathrm{Br}_{\mathrm{x}}$ $\left(\mathrm{Br}+\mathrm{BrO}+\mathrm{HOBr}+2 \mathrm{Br}_{2}+\mathrm{BrCl}\right)$ when these reactions are taken into account. There is slightly more $\mathrm{Br}_{\mathrm{x}}$ in the upper troposphere in Fig. 14b compared with Fig. 14a. Adding Reaction (R12) leads to more conversion to the soluble species $\mathrm{HOBr}$ to $\mathrm{BrCl}$ which is much less soluble. This leads to more $\mathrm{Br}_{\mathrm{x}}$ lifted to the upper troposphere. On the contrary, we can observe, with comparison of Figs. 14a and 14b, that slightly less $\mathrm{Br}_{\mathrm{X}}$ is produced in the lower troposphere at the edge of the convective system. This is because the production of $\mathrm{BrCl}$ leads to a decrease of the production of $\mathrm{Br}_{2}$. The bromine explosion is therefore reduced since the formation of $\mathrm{BrCl}$ by Reaction (R12) does not lead to a loss of $\mathrm{Br}^{-}$contrary to Reaction (R4).

Figure $14 \mathrm{c}$ shows the comparison of the mean profile of $\mathrm{Br}_{\mathrm{x}}$ lifted in the upper troposphere at the end of the con- vective event $\left(t_{0}+110 \mathrm{mn}\right)$ for three cases: firstly, no formation of $\mathrm{BrCl}$ and cloud $\mathrm{pH}=4$; secondly, no formation of $\mathrm{BrCl}$ and cloud $\mathrm{pH}=5$; and thirdly, formation of $\mathrm{BrCl}$ is considered assuming $\mathrm{pH}=5$ and $\left[\mathrm{Cl}^{-}\right]=5 \times 10^{-4} \mathrm{moll}^{-1}$. As shown previously, adding the reaction for the formation of $\mathrm{BrCl}$ causes a small increase of $\mathrm{Br}_{\mathrm{x}}$. Since the chloride ion concentration assumed in the simulation is a maximum value, this impact can be neglected in all other cases.

\subsubsection{The PERT2 simulation}

The PERT2 simulation is made under the same conditions as the PERT1 simulation. Only the initial mixing ratio of $\mathrm{CHBr}_{3}$ is different. It is $1.6 \mathrm{pptv}$ instead of 40 pptv, i.e. a factor 25 less. Similar to BG2 and BG1, in the case of PERT 2 the mixing ratios of all the species just before the convective event are also 25 times less abundant than in PERT1. Figure 15 shows the mean profiles of inorganic PGs, organic PGs and $\mathrm{CHBr}_{3}$ in the upper troposphere for a cloud $\mathrm{pH}=5$ (Fig. 15a) and for a cloud $\mathrm{pH}=4$ (Fig. 15c), and in the TTL for cloud $\mathrm{pH}=5$ (Fig. 15b) and cloud $\mathrm{pH}=4$ (Fig. 15d). The 

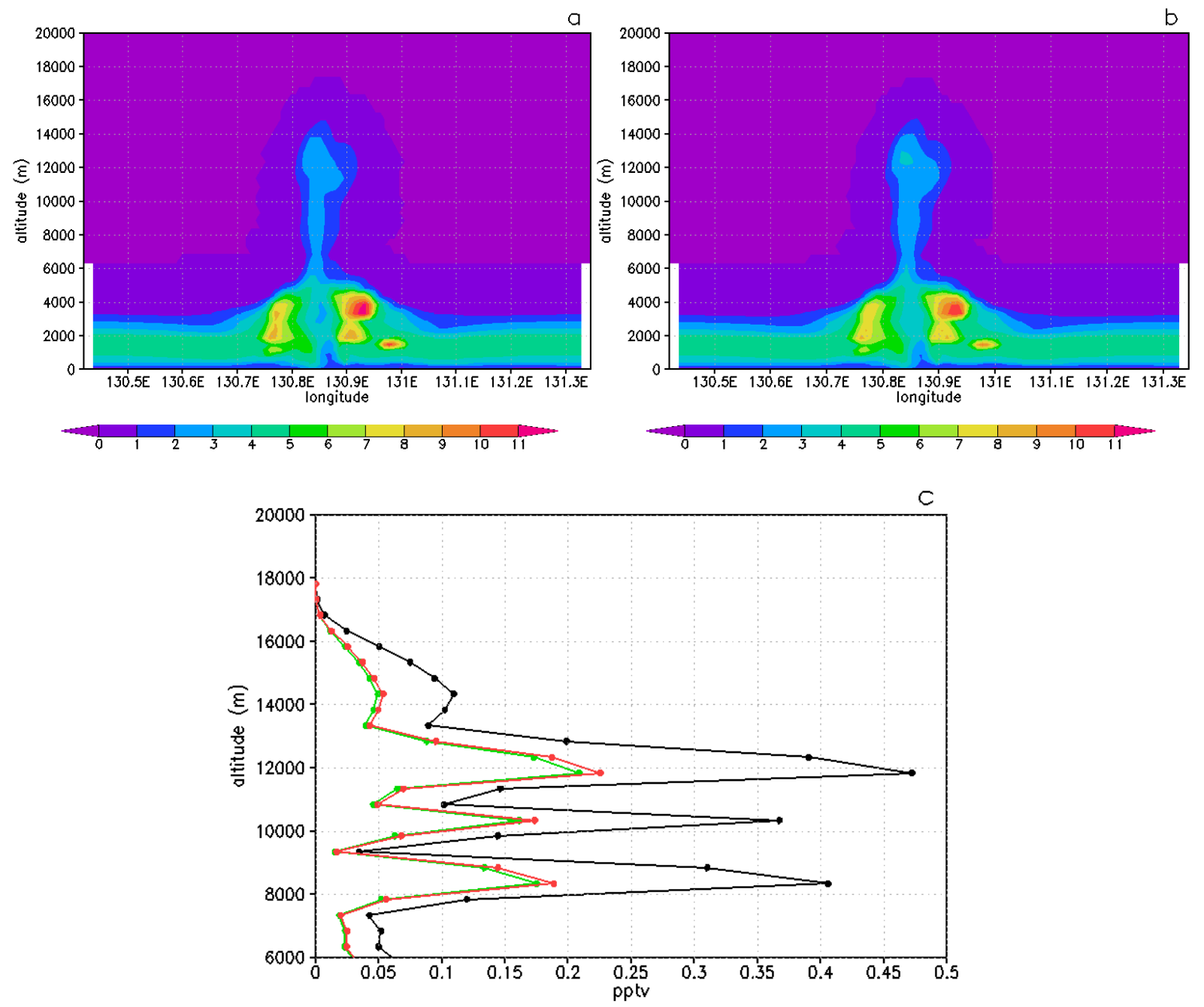

Fig. 14. Longitude-altitude cross-section at the latitude $-12.4^{\circ} \mathrm{S}$ from the PERT1 simulation at $t_{0}+30 \mathrm{mn}$ of (a) $\mathrm{Br}_{\mathrm{X}}$ $(\mathrm{Br}+\mathrm{BrO}+\mathrm{HOBr}+2 \cdot \mathrm{Br} 2)$ for cloud $\mathrm{pH}=5$ with no chlorine chemistry, $(\mathbf{b}) \mathrm{Br}_{\mathrm{x}}(\mathrm{Br}+\mathrm{BrO}+\mathrm{HOBr}+2 \cdot \mathrm{Br} 2+\mathrm{BrCl})$ for cloud $\mathrm{pH}=5$ with chlorine chemistry, and (c) mean profile averaged on the horizontal of $\mathrm{Br}_{\mathrm{X}}$ at the end of the convective event $\left(t_{0}+110 \mathrm{mn}\right)$ for cloud $\mathrm{pH}=4$ with no chlorine chemistry black), $\mathrm{Br}_{\mathrm{x}}$ for cloud $\mathrm{pH}=5$ with no chlorine chemistry (green), $\mathrm{Br}_{\mathrm{x}}$ with chlorine chemistry for cloud $\mathrm{pH}=5$ (red).

mixing ratios shown in Fig. 15 are relatively low compared to the peak values because of the horizontal averaging used in Fig. 15. The profiles of $\mathrm{CHBr}_{3}$ and the organic PGs approximately remain in the same ratio of 25 compared to the profiles computed in the PERT1 simulation (Fig. 13). This is because under these limited conditions the $\mathrm{CHBr}_{3}$ and the organic PGs' chemistry closely approximates first order rate kinetics with respect to bromine atoms, i.e. the response of the rate of chemical conversion of brominated species for all relevant reactions is very closely linear with respect to the initial abundance of the reactant $\mathrm{CHBr}_{3}$. The ratio is not exactly 25 because the lower abundance of $\mathrm{CHBr}_{3}$ in the PERT2 simulation increases the $\mathrm{OH}$ radical abundance, which leads to a very small decrease in the $\mathrm{CHBr}_{3}$ lifetime.
On the contrary, the mixing ratios of the inorganic PGs do not remain proportional to the initial $\mathrm{CHBr}_{3}$ mixing ratio. This is because the reaction of $\mathrm{HOBr}_{\mathrm{C}}+\mathrm{Br}^{-} \rightarrow \mathrm{Br}_{2 \mathrm{~g}}$ is second order with respect to bromine atoms, which are present in both reactants. Therefore, as a result of the reduction of initial $\mathrm{CHBr}_{3}$ mixing ratio between PERT1 and PERT2 the reaction of $\mathrm{HOBr}_{\mathrm{C}}+\mathrm{Br}^{-} \rightarrow \mathrm{Br}_{2 \mathrm{~g}}$ is disproportionately less efficient since it depends on both the $\mathrm{Br}$ - and $\mathrm{HOBr}$ concentrations. As in PERT1, more inorganic PGs are produced for cloud $\mathrm{pH}=4$ than for cloud $\mathrm{pH}=5$. This is due to the impact of the reaction $\left(\mathrm{HOBr}_{\mathrm{C}}+\mathrm{Br}^{-} \rightarrow \mathrm{Br}_{2 \mathrm{~g}}\right)$ in the aqueous phase leading to increased $\mathrm{Br}_{2}$ formation.

Using Fig. 15, we observe that relative to the total bromine atom abundance at $12 \mathrm{~km}$, the inorganic PGs only represent $2.4 \%$ of that budget for $\mathrm{pH}=5$ and $3.1 \%$ for $\mathrm{pH}=4$. In the 

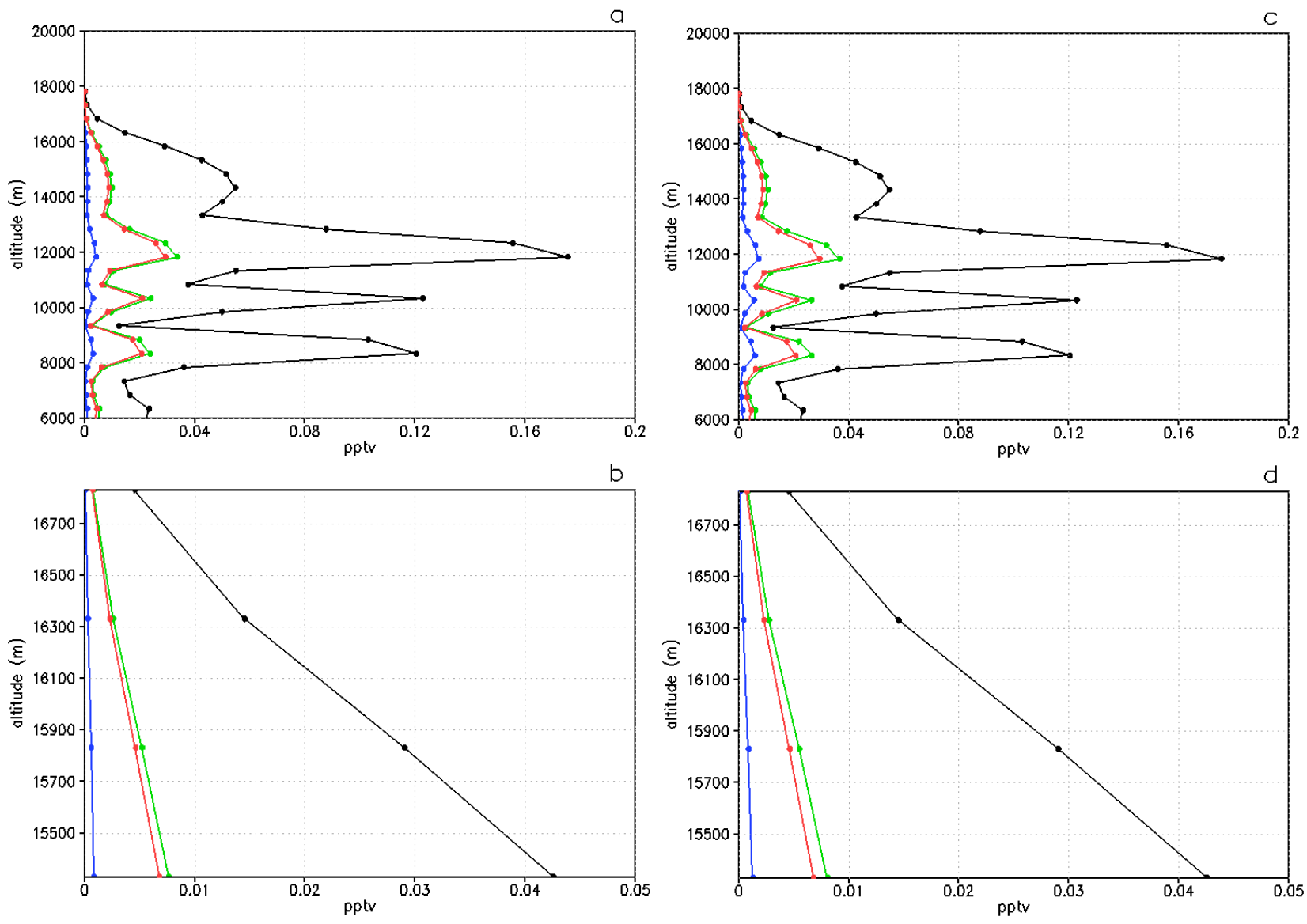

Fig. 15. Same as Fig. 13 for the PERT2 simulation.

TTL they are $2 \%$ and $2.8 \%$, respectively. In this case, only organic PGs and $\mathrm{CHBr}_{3}$ are transported significantly to the upper troposphere and to the TTL.

\section{Conclusions}

Bromoform is known to be one of the most abundant halogenated VSLS that could influence the bromine loading in the stratosphere. Tropical convection is the main pathway for bromoform and its product gases (PGs) to the TTL. From the TTL they can enter the stratosphere via radiative ascent. In this paper we present a detailed study of the transport and degradation of bromoform and its PGs in convective conditions at the cloud scale. The objective is to evaluate the relative importance of the different processes affecting the spatial distribution of bromoform and its product gases under convective conditions, in particular the interactions of PGs with the liquid cloud and rain. We use the 3-D cloud resolving model with tracer transport CATT-BRAMS coupled online with a chemistry model. The chemistry model includes gaseous chemistry, photolysis, $\mathrm{BrONO}_{2}$ hydrolysis, aqueous chemistry of bromine species and dry deposition. This model is more detailed than what is used in current global models.
In particular we take into account the aqueous chemistry including the production of $\mathrm{Br}_{2}$ in the gas phase via the reactions in the aqueous phase. A limitation of running over such a small spatial domain and with idealised conditions is that we can not make conclusions about the global budget of bromoform and its PGs.

For this study at the convective scale, we used idealized meteorological conditions from a tropical radiosounding launched during the convective season in North Australia. Four simulations were done. Two BG (background) simulations corresponding to stable atmospheric conditions were run for 10 days. In the first one, the initial bromoform mixing ratio is assumed to be the maximum measured value. In the second one the initial bromoform mixing ratio is the measured mean value. Two PERT (perturbed) simulations were also done. The PERT simulations are similar to the BG simulations except that temperature and moisture perturbations were applied in the lowest $2 \mathrm{~km}$ layer after 5 days and $6 \mathrm{~h}$ leading to the development of a convective cloud reaching the TTL. The results of the BG simulations show that bromoform mixing ratios in the boundary layer decreases over time and those of PGs increase with time. Product gases are mainly in the form of $\mathrm{HBr}$ and organic products. Because 
of dry deposition the sum of bromoform and PGs decreases with time. Resulting PG mixing ratios are proportional to the initial bromoform mixing ratio chosen.

In the PERT simulations a significant proportion of $\mathrm{CHBr}_{3}$ is transported by convection into the upper troposphere and the TTL because it is not a soluble species. Organic species, which are for the most abundant of them not very soluble, are also efficiently lifted to the TTL. More than $13 \%$ of the bromine atoms lifted to the TTL by the convective event are in the form of organic $\mathrm{PGs}\left(\mathrm{CBr}_{2} \mathrm{O}\right.$ and $\left.\mathrm{CHBrO}\right)$ in both PERT simulations.

The quantity of inorganic PGs reaching the upper troposphere and the TTL depends tightly on the interactions between the gas phase and the aqueous phase. The results clearly show that one important process in the partitioning of inorganic PGs between soluble and non-soluble species is the formation of $\mathrm{Br}_{2}$ within cloud droplets containing dissolved $\mathrm{HOBr}$ and $\mathrm{HBr}$ and its subsequent release to the gas phase. This reaction favours the formation of non soluble inorganic PGs and reduces $\mathrm{HBr}$ and $\mathrm{HOBr}$ scavenging leading to an increase of non-soluble inorganic $\mathrm{PG}$ mixing ratios in the upper troposphere and in the TTL. This process depends on the cloud droplet acidity and is significantly more efficient in polluted conditions (high acidity).

A sensitivity test has been done to evaluate the possible impact of chlorine chemistry in the production of non-soluble species in the aqueous phase. Reactions involving $\mathrm{HOCl}$, $\mathrm{Cl}^{-}$and bromine species could lead to the production of the non-soluble species $\mathrm{BrCl}$. The photolysis of this species is very fast. It leads to the production of $\mathrm{Br}_{\mathrm{x}}$ species which can be transported to the upper troposphere by convection. Nevertheless, since hydrolysis of $\mathrm{BrCl}$ in the aqueous phase $\left(\mathrm{BrCl}+\mathrm{H}_{2} \mathrm{O} \rightarrow \mathrm{HOBr}+\mathrm{Cl}^{-}+\mathrm{H}^{+}\right)$is very fast only a small fraction of $\mathrm{BrCl}$ produced in the cloud droplet can be released to the gas phase except if $\mathrm{BrCl}$ reacts with $\mathrm{Br}^{-}$to produce $\mathrm{Br}_{2}\left(\mathrm{Br}^{-}+\mathrm{BrCl} \rightarrow \mathrm{Br}_{2}+\mathrm{Cl}^{-}\right)$. With the present knowledge, only a minimum value of the rate constant for this reaction is known. Because of the low bromide ion concentration in the cloud droplets, it is not possible to know in our case if the rate at which $\mathrm{BrCl}$ reacts with $\mathrm{Br}^{-}\left(>\sim 10 \mathrm{~s}^{-1}\right)$ is sufficiently large to take place compared with the diffusion rate of $\mathrm{BrCl}$ out of the cloud droplet $\left(\sim 2 \times 10^{3} \mathrm{~s}^{-1}\right)$. In this case, and without further information, it seems that chlorine chemistry has a small impact on the production of $\mathrm{Br}_{\mathrm{x}}$. Therefore, in this paper we assumed that $\mathrm{BrCl}$ does not react with $\mathrm{Br}^{-}$. In the PERT1 simulation, $9.5 \%$ of the bromine atoms lifted to $12 \mathrm{~km}$ by the convective event are in the form of inorganic PGs if cloud $\mathrm{pH}=4$. It is $6.6 \%$ in the TTL. It is $4.5 \%$ at $12 \mathrm{~km}$ and $3.5 \%$ in the TTL if cloud $\mathrm{pH}=5$. In the PERT2 simulation less than $3 \%$ of the bromine atoms are transported to the TTL as inorganic PGs. Inorganic species can therefore be transported in significant quantities to the TTL only in cases of large bromoform emissions. This conclusion will have to be revisited if $\mathrm{BrCl}$ can react efficiently with $\mathrm{Br}^{-}$.
A more precise value of the rate constant for this reaction is needed.

There are several other sources of uncertainties in this study. Firstly, the results depend strongly on the Henry's constants for inorganic PGs that were determined here theoretically by Krysztofiak et al. (2012). They need to be confirmed by experimental measurements. Secondly, the simulations were run in idealized convective conditions. In real conditions, several parameters could be different from those used in the PERT simulations. This could lead to a different proportion of PGs (organic and inorganic) lifted by convection to the TTL. The differences between idealised and real conditions that are expected to lead to significant differences in the results are:

- the relative concentrations of organic and inorganic PGs with respect to $\mathrm{CHBr}_{3}$ before convection starts,

- the concentrations of soluble and low solubility organic and inorganic PGs before convection starts,

- the concentration and size distribution of liquid cloud droplets and raindrops produced by convection,

- the $\mathrm{pH}$ of liquid cloud particles.

To go a step further, simulations of real case studies are required. This will be possible in the frame of the SHIVA European project and the NASA SEAC ${ }^{4}$ RS. One objective of these projects is the understanding of the chemistry and pathways to the stratosphere of halogenated VSLSs. These field campaigns will provide validation data for model simulations. In the case of SHIVA, aircraft based observations of VSLS at cloud scale will help to validate the transport modelling and place loose constraints on the chemistry, and ship borne observations of VSLS, $\mathrm{BrO}, \mathrm{Br}_{2}, \mathrm{HOBr}$, and $\mathrm{HBr}$ will help to validate the chemistry in the model. During SEAC ${ }^{4} \mathrm{RS}$ observations of $\mathrm{BrO}, \mathrm{HOBr}$, and VSLS will provide more detailed validation of the chemistry and further support the transport modelling. Once validated in real case studies, the results on the partitioning between $\mathrm{CHBr}_{3}$, organic and inorganic PGs reaching the TTL could be taken into account in global models via parameterizations.

Two issues which have not been discussed in the paper are the transport of species transferred from cloud to ice particles during the riming process and the interaction between PGs in the gas phase and the ice particles in the atmosphere. Most of the species transferred by riming in the ice phase are rapidly washed out because most rimed particles are dense and therefore fast-falling. But the small proportion of species that are transferred by riming to small slow-falling ice particles could be transported to the TTL and possibly released to the gas phase by sublimation. This could be taken into account in a future study. The interaction between PGs and ice particles has not been included in our chemistry model although it was taken into account by Aschmann et al. (2011) 
in their simulations at the global scale. For our study of bromoform at the local scale, this process is likely not very important since only a very small amounts of $\mathrm{HBr}$ reaches altitude levels where ice particles grow by water deposition. This is because $\mathrm{HBr}$ is efficiently scavenged by cloud and rain below and cannot therefore be transported to the upper troposphere where ice is present. Nevertheless, this process is likely important several hours after convective events in the cirrus layer that generally remain after convection. At this cloud stage $\mathrm{HBr}$ can be produced from inorganic PGs transported by convection into the upper troposphere and the TTL and interact with ice particles.

\section{Appendix A}

Production of $\mathrm{Br}_{2}$ in the gas phase via the reactions in the aqueous phase

For $\mathrm{Br}_{2}$, the Eqs. (1), (2) and (3) can be written:

$$
\begin{aligned}
& \frac{\mathrm{d}\left[\mathrm{Br}_{2}\right]_{\mathrm{g}}}{\mathrm{d} t}=\frac{k_{\mathrm{C}}}{H R T}\left[\mathrm{Br}_{2}\right]_{\mathrm{C}}-k_{\mathrm{C}} V_{\mathrm{C}}\left[\mathrm{Br}_{2}\right]_{\mathrm{g}}+\frac{k_{\mathrm{R}}}{H R T}\left[\mathrm{Br}_{2}\right]_{\mathrm{R}} \\
& \quad-k_{\mathrm{R}} V_{\mathrm{R}}\left[\mathrm{Br}_{2}\right]_{\mathrm{g}}+P_{\mathrm{g}}-L_{\mathrm{g}}\left[\mathrm{Br}_{2}\right]_{\mathrm{g}}
\end{aligned}
$$

$$
\begin{gathered}
\frac{\mathrm{d}\left[\mathrm{Br}_{2}\right]_{\mathrm{C}}}{\mathrm{d} t}=k_{2}\left[\mathrm{Br}^{-}\right]_{\mathrm{C}}\left[\mathrm{H}^{+}\right]_{\mathrm{C}}[\mathrm{HOBr}]_{\mathrm{C}}-k_{3}\left[\mathrm{Br}_{2}\right]_{\mathrm{C}} \\
-\frac{k_{\mathrm{C}}}{H R T}\left[\mathrm{Br}_{2}\right]_{\mathrm{C}}+k_{\mathrm{C}} V_{\mathrm{C}}\left[\mathrm{Br}_{2}\right]_{\mathrm{g}}
\end{gathered}
$$

$$
\begin{gathered}
\frac{\mathrm{d}\left[\mathrm{Br}_{2}\right]_{\mathrm{R}}}{\mathrm{d} t}=k_{2}\left[\mathrm{Br}^{-}\right]_{\mathrm{R}}\left[\mathrm{H}^{+}\right]_{\mathrm{R}}[\mathrm{HOBr}]_{\mathrm{R}}-k_{3}\left[\mathrm{Br}_{2}\right]_{\mathrm{R}} \\
-\frac{k_{\mathrm{R}}}{H R T}\left[\mathrm{Br}_{2}\right]_{\mathrm{R}}+k_{\mathrm{R}} V_{\mathrm{R}}\left[\mathrm{Br}_{2}\right]_{\mathrm{g}}
\end{gathered}
$$

where

- $\left[\mathrm{Br}_{2}\right]_{\mathrm{C}},\left[\mathrm{Br}_{2}\right]_{\mathrm{R}},[\mathrm{HOBr}]_{\mathrm{C}}[\mathrm{HOBr}]_{\mathrm{R}}$ are the concentrations of $\mathrm{Br}_{2}$ and $\mathrm{HOBr}$ per $\mathrm{cm}^{3}$ of air in cloud droplets and raindrops, respectively,

- $\left[\mathrm{Br}_{2}\right]_{\mathrm{g}}$ is the concentration of $\mathrm{Br}_{2}$ in the gas phase,

- $\left[\mathrm{Br}^{-}\right]_{\mathrm{C}},\left[\mathrm{Br}^{-}\right]_{\mathrm{R}},\left[\mathrm{H}^{+}\right]_{\mathrm{C}}$ and $\left[\mathrm{H}^{+}\right]_{\mathrm{R}}$ are the concentrations (in mol per 1 of water) of bromine ions and $\mathrm{pH}$ in the cloud or the rain droplets,

- $k_{\mathrm{C}}$ and $k_{\mathrm{R}}$ are the mass transfer coefficients of $\mathrm{Br}_{2}$ in cloud and rain, respectively,

- $H$ is the $\mathrm{Br}_{2}$ Henry's coefficient,

- Pg and $\mathrm{Lg}$ are the production and loss term of $\mathrm{Br}_{2}$ in the gas phase,

- $V_{\mathrm{C}}, V_{\mathrm{R}}, k_{2}$ and $k_{3}$ are defined in Sect. 2.2.
Since the loss terms of Eqs. (A2) and (A3) are very large, the equilibrium is reached rapidly leading to:

$$
\begin{aligned}
& \left(k_{3}+\frac{k_{\mathrm{C}}}{H R T}\right)\left[\mathrm{Br}_{2}\right]_{\mathrm{C}}=k_{2}\left[\mathrm{Br}^{-}\right]_{\mathrm{C}}\left[\mathrm{H}^{+}\right]_{\mathrm{C}}[\mathrm{HOBr}]_{\mathrm{C}} \\
& \quad+k_{\mathrm{C}} V_{\mathrm{C}}\left[\mathrm{Br}_{2}\right]_{\mathrm{g}} \\
& \left(k_{3}+\frac{k_{\mathrm{R}}}{H R T}\right)\left[\mathrm{Br}_{2}\right]_{\mathrm{R}}=k_{2}\left[\mathrm{Br}^{-}\right]_{\mathrm{R}}\left[\mathrm{H}^{+}\right]_{\mathrm{R}}[\mathrm{HOBr}]_{\mathrm{R}} \\
& \quad+k_{\mathrm{R}} V_{\mathrm{R}}\left[\mathrm{Br}_{2}\right]_{\mathrm{g}}
\end{aligned}
$$

Using Eqs. (A4) and (A5) and assuming $\frac{k_{\mathrm{C}}}{H R T} \gg k_{3} \gg \frac{k_{\mathrm{R}}}{H R T}$ as discussed in Sect. 2.2, Eq. (A1) can be written:

$$
\begin{gathered}
\frac{\mathrm{d}\left[\mathrm{Br}_{2}\right]_{\mathrm{g}}}{\mathrm{d} t}=k_{2}\left[\mathrm{Br}^{-}\right]_{\mathrm{C}}\left[\mathrm{H}^{+}\right]_{\mathrm{C}}[\mathrm{HOBr}]_{\mathrm{C}}+k_{2} \frac{k_{\mathrm{R}}}{k_{3} H R T} \\
{\left[\mathrm{Br}^{-}\right]_{\mathrm{R}}\left[\mathrm{H}^{+}\right]_{\mathrm{R}}[\mathrm{HOBr}]_{\mathrm{R}}-k_{3} H R T V_{\mathrm{C}}\left[\mathrm{Br}_{2}\right]_{\mathrm{g}}} \\
-k_{\mathrm{R}} V_{\mathrm{R}}\left[\mathrm{Br}_{2}\right]_{\mathrm{g}}+P_{\mathrm{G}}-L_{\mathrm{G}}\left[\mathrm{Br}_{2}\right]_{\mathrm{g}}
\end{gathered}
$$

If the concentrations of $\mathrm{Br}^{-}$and $\mathrm{HOBr}$ were equal in the cloud and rain droplets and if the volume of the rain and cloud droplets were also equal, the second term and the fourth term, which apply to rain droplets, would approximately be 10 times lower than the first and the third terms, which apply to cloud droplets. In the simulations, the concentrations of bromine ions $\left(\mathrm{Br}^{-}\right)$and $\mathrm{HOBr}$ in the cloud droplets compared with those in the rain droplets are varying as a function of the grid point and of the time. Cloud and rain volumes are also varying. Nevertheless, at the beginning of the formation of the convective event, i.e. approximately from $t_{0}+15 \mathrm{~min}$ to $t_{0}+25 \mathrm{~min}$ ( $t_{0}$ is defined in Sect. 3.2), they are of the same order of magnitude on average. It is in this time interval that $\mathrm{Br}_{2}$ is produced. It is then possible to neglect the second and fourth terms of Eq. (A6). Equation (A6) is finally written in the simplified final form:

$$
\begin{gathered}
\frac{\mathrm{d}\left[\mathrm{Br}_{2}\right]_{\mathrm{g}}}{\mathrm{d} t}=k_{2}\left[\mathrm{Br}^{-}\right]_{\mathrm{C}}\left[\mathrm{H}^{+}\right]_{\mathrm{C}}[\mathrm{HOBr}]_{\mathrm{C}}-k_{3} H R T V_{\mathrm{C}} \\
{\left[\mathrm{Br}_{2}\right]_{\mathrm{g}}+P_{\mathrm{G}}-L_{\mathrm{G}}\left[\mathrm{Br}_{2}\right]_{\mathrm{g}}}
\end{gathered}
$$

Acknowledgements. This work is supported by the EU project SHIVA (226224-FP7-ENV-2008-1). The numerical simulations were performed on the cluster of the Centre de Calcul Scientifique en Région Centre. CATT-BRAMS is a free software provided by CPTEC/INPE and distributed under the CC-GNU-GPL license. We also thank John Crowley for fruitful discussions on this work.

Edited by: A. Engel

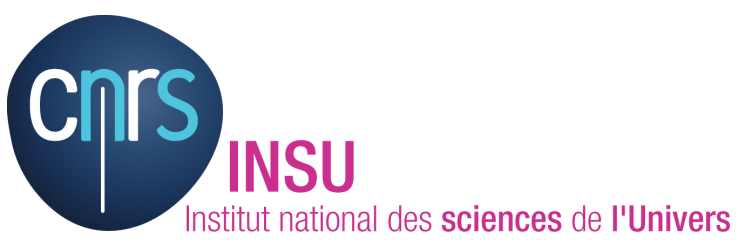

The publication of this article is financed by CNRS-INSU. 


\section{References}

Arteta, J., Marécal, V., and Rivière, E. D.: Regional modelling of tracer transport by tropical convection - Part 1: Sensitivity to convection parameterization, Atmos. Chem. Phys., 9, 70817100, doi:10.5194/acp-9-7081-2009, 2009.

Aschmann, J., Sinnhuber, B.-M., Atlas, E. L., and Schauffler, S. M.: Modeling the transport of very short-lived substances into the tropical upper troposphere and lower stratosphere, Atmos. Chem. Phys., 9, 9237-9247, doi:10.5194/acp-9-9237-2009, 2009.

Aschmann, J., Sinnhuber, B.-M., Chipperfield, M. P., and Hossaini, R.: Impact of deep convection and dehydration on bromine loading in the upper troposphere and lower stratosphere, Atmos. Chem. Phys., 11, 2671-2687, doi:10.5194/acp-11-2671-2011, 2011.

Atkinson, R., Baulch, D. L., Cox, R. A., Crowley, J. N., Hampson, R. F., Hynes, R. G., Jenkin, M. E., Rossi, M. J., and Troe, J.: Evaluated kinetic and photochemical data for atmospheric chemistry: Volume III - gas phase reactions of inorganic halogens, Atmos. Chem. Phys., 7, 981-1191, doi:10.5194/acp-7-981-2007, 2007.

Barrie, L. A., Bottenheim, J. W., Schnell, R. C., Crutzen, P. J., and Rasmussen, R. A.: Ozone destruction and photochemical reactions at polar sunrise in the lower arctic atmosphere, Nature, 334, 138-141, 1988.

Barth, M. C., Stuart, A. L., and Skamarock, W. C.: Numerical simulations of the July 10, 1996, Stratospheric-Tropospheric experiment: Radiation, aerosols and ozone (STERAO)-Deep convection experiment storm: Redistribution of soluble tracers, J. Geophys. Res., 106, 12381-12400, 2001.

Barth, M. C., Sillman, S., Hudman, R., Jacobson, M. Z., Kim, C.-H., Monod, A., and Liang, J.: Summary of the cloud chemistry modelling intercomparison: Photochemical box model simulation, J. Geophys. Res., 108, 4214, doi:10.1029/2002JD002673, 2003.

Barth, M. C., Kim, S.-W., Skamarock, W. C., Stuart, A. L., Pickering, K. E., and Ott, L. E.: Simulations of the redistribution of formaldehyde, fomic acid, and peroxides in the July 1996 stratospheric-tropospheric experiment: radiation, aerosols and ozone deep convection storm, J. Geophys. Res., 112, D13310, doi:10.1029/2006JD008046, 2007.

Bousserez, N., Attié, J.-L., Peuch, V.-H., Michou, M., Pfister, G., Edwards, D., Avery, M., Sachse, G., Browell, E., and Ferrare, E.: Evaluation of MOCAGE chemistry and transport model during the ICARTT/ITOP experiment, J. Geophys. Res., 112, D120S42, doi:10.1029/2006JD007595, 2007.

Brinckmann, S., Engel, A., Bönisch, H., Quack, B., and Atlas, E.: Short-lived brominated hydrocarbons - observations in the source regions and the tropical tropopause layer, Atmos. Chem. Phys., 12, 1213-1228, doi:10.5194/acp-12-1213-2012, 2012.

Brioude, J., Portmann, R. W., Daniel, J. S., Cooper, O. R., Frost, G. J., Rosenlof, K. H., Granier, C., Ravishankara, A. R., Montkza, S. A., and Sthol, A.: Variations in ozone depletion potentials of very short-lived substances with season and emission region, Geophys. Res. Lett., 37, L19804, doi:10.1029/2010GL044856, 2010.

Chang, C. T., Liu, T. H., and Jeng, F.-T.: Atmospheric concentrations of the $\mathrm{Cl}$ atom, $\mathrm{ClO}$ radical, and $\mathrm{HO}$ radical in the coastal marine boundary layer, Environ. Res., 94, 67-74, 2004.

Dorf, M., Butz, A., Camy-Peyret, C., Chipperfield, M. P., Kritten, L., and Pfeilsticker, K.: Bromine in the tropical troposphere and stratosphere as derived from balloon-borne $\mathrm{BrO}$ observations,
Atmos. Chem. Phys., 8, 7265-7271, doi:10.5194/acp-8-72652008, 2008.

Eigen, M. and Kustin, K.: The Kinetics of Halogen hydrolysis, J. Am. Chem. Soc., 84, 1355-1361, 1962.

Fickert, S., Adams, J. W., and Crowley, J. N.: Activation of $\mathrm{Br}_{2}$ and $\mathrm{BrCl}$ via uptake of $\mathrm{HOBr}$ onto aqueous salt solutions, J. Geophys. Res., 104, 23719-23727, 1999.

Finlayson-Pitts, B. J: Chlorine atoms as a potential tropospheric oxidant in the marine boundary layer, Res. Chem. Intermediat., 19, 235-249, 1993.

Freitas, S. R., Longo, K. M., Silva Dias, M. A. F., Chatfield, R., Silva Dias, P., Artaxo, P., Andreae, M. O., Grell, G., Rodrigues, L. F., Fazenda, A., and Panetta, J.: The Coupled Aerosol and Tracer Transport model to the Brazilian developments on the Regional Atmospheric Modeling System (CATT-BRAMS) - Part 1: Model description and evaluation, Atmos. Chem. Phys., 9, 28432861, doi:10.5194/acp-9-2843-2009, 2009.

Fueglistaler, S., Dessler, A. E., Dunkerton, T. J., Folkins, I., Fu, Q., and Mote, P. W.: Tropical tropopause layer, Rev. Geophys., 47, RG1004, doi:10.1029/2008RG000267, 2009.

Gettelmann, A., Lauritzen, P. H., Park, M., and Kay, J. E.: Processes regulating short-lived species in the tropical tropopause layer, J. Geophys. Res., 114, D13303, doi:10.1029/2009JD011785, 2009.

Graedel, T. E. and Keene, W. C.: Tropospheric budget of reactive chlorine, Global Biogeochem. Cy., 9, 47-77, 1995.

Hossaini, R., Chipperfield, M. P., Monge-Sanz, B. M., Richards, N. A. D., Atlas, E., and Blake, D. R.: Bromoform and dibromomethane in the tropics: a 3-D model study of chemistry and transport, Atmos. Chem. Phys., 10, 719-735, doi:10.5194/acp10-719-2010, 2010.

Hossaini, R., Chipperfield, M. P., Feng, W., Breider, T. J., Atlas, E., Montzka, S. A., Miller, B. R., Moore, F., and Elkins, J.: The contribution of natural and anthropogenic very short-lived species to stratospheric bromine, Atmos. Chem. Phys., 12, 371380, doi:10.5194/acp-12-371-2012, 2012.

Hoyle, C. R., Marécal, V., Russo, M. R., Allen, G., Arteta, J., Chemel, C., Chipperfield, M. P., D’Amato, F., Dessens, O., Feng, W., Hamilton, J. F., Harris, N. R. P., Hosking, J. S., Lewis, A. C., Morgenstern, O., Peter, T., Pyle, J. A., Reddmann, T., Richards, N. A. D., Telford, P. J., Tian, W., Viciani, S., Volz-Thomas, A., Wild, O., Yang, X., and Zeng, G.: Representation of tropical deep convection in atmospheric models - Part 2: Tracer transport, Atmos. Chem. Phys., 11, 8103-8131, doi:10.5194/acp-118103-2011, 2011.

Jaeglé, L., Jacob, D. J., Brune, W. H., and Wennberg, P. O.: Chemistry of $\mathrm{HO}_{\mathrm{x}}$ radicals in the upper troposphere, Atmos. Environ., 35, 469-489, 2001.

Josse, B., Simon, P., and Peuch, V.-H.: Radon global simulations with the multiscale chemistry and transport model MOCAGE, Tellus B, 56, 339-356, 2004.

Krysztofiak, G., Catoire, V., Poulet, G., Marécal, V., Pirre, M., Louis, F., Canneaux, S., and Josse, B.: Detailed modeling of the atmospheric degradation mechanism of very short-lived brominated species, Atmos. Environ., 59, 514-532, 2012.

Kumar, K. and Margerum, D. W.: Kinetics and mechanism of general-acid assisted oxidation of bromide by hypochlorite and hypochlorous acid, Inorg. Chem., 26, 2706-2711, 1987.

Lefèvre, F., Brasseur, G. P., Folkins, I., Smith, A. K., and Simon, P.: Chemistry of the 1991-1992 stratospheric winter: 
three-dimensional model simulations, J. Geophys. Res., 99, 8183-8195, 1994.

Mellor, G. and Yamada, T.: Development of a turbulence closure model for geophysical fluid problems, Rev. Geophys., 20, 851875, 1982.

Meylan, W. M. and Howard, P. H.: Bond contribution method for estimating Henry's law constants, Environ. Toxicol. Chem., 10, 1283-1293, 1991.

Montzka, S. A., Reimann, S., O’Doherty, S., Engel, A., Krüger, K., and Sturges, W. T.: Ozone-Depleting Substances (ODSs) and Related Chemicals, Chapter 1 in Scientific Assessment of Ozone Depletion: 2010, Global Ozone Research and Monitoring Project - Report No. 52, World Meteorological Organization, Geneva, 2011.

Nirmalakhandan, N. N. and Speece, R. E.: Prediction of Aqueous Solubility of Organic Chemicals Based on Molecular Structure, Environ. Sci. Technol., 22, 328-338, 1988.

Pisso, I., Haynes, P. H., and Law, K. S.: Emission location dependent ozone depletion potentials for very short-lived halogenated species, Atmos. Chem. Phys., 10, 12025-12036, doi:10.5194/acp-10-12025-2010, 2010.

Quack, B. and Wallace, D. W. R.: Air-sea flux of bromoform: Controls, rates, and implications, Global Biogeochem. Cy., 17, 1023, doi:10.1029/2002GB001890, 2003.

Sander, R.: Compilation of Henry's Law Constants for Inorganic and Organic Species of Potential Importance in Environmental Chemistry (Version 3) http://www.henrys-law.org, 1999 (last update 19 August 2011).

Sander, R. and Crutzen, P. J.: Model study indicating halogen activation and ozone destruction in polluted air mass transported to the sea, J. Geophys. Res., 101, 9121-9138, 1996.

Sander, S. P., Ravishankara, A. R., Golden, D. M., Kolb, C. E., Kurylo, M. J., Molina, M. J., Moortgat, G. K., Finlayson-Pitts, B. J., Wine, P. H., and Huie, R. E.: Chemical Kinetics and Photochemical Data for Use in Atmospheric Studies Evaluation Number 15, JPL Publication 06-2, 2006.

Sandu, A., Verwer, J. G., Blom, J. G., and Spee, E. J.: Benchmarking stiff ode solvers for atmospheric chemistry problems II : Rosenbrock solvers, Atmos. Environ., 31, 3459-3472, 1997.

Schofield, R., Fueglistaler, S., Wohltmann, I., and Rex, M.: Sensitivity of stratospheric Bry to uncertainties in very short lived substance emissions and atmospheric transport, Atmos. Chem. Phys., 11, 1379-1392, doi:10.5194/acp-11-1379-2011, 2011.

Sinnhuber, B.-M., Rosanov, A., Sheode, N., Afe, O. T., Richter, A., Sinnhuber, M., Wottrock, F., Burrows, J. P., Stiller, G. P., von Clarmann, T., and Linden, A.: Global observations of stratospheric bromine monxide from SCIAMACHY, Geophys. Res. Lett., 32, L20810, doi:10.1029/2005GL023829, 2005.

Spivakovsky, C. M., Logan, J. A. Montzka, S. A., Balkanski, Y. J., Foreman-Fowler, M., Jones, D. B. A., Horowitz, L. W., Fusco, A. C., Brenninkmeijer, C. A. M., Prather, M. J., Wofsy, S. C., and McElroy, M. B.: Three-dimensional climatological distribution of troposheric $\mathrm{OH}$ : update and evaluation, J. Geophys. Res., 105, D7, doi:10.1029/1999JD901006, 2000.
Stockwell, W. R., Kirchner, F., Kuhn, M., and Seefeld, S.: A New Mechanism for Regional Atmospheric Chemistry Modeling, J. Geophys. Res., 102, 25847-25879, 1997.

Tan, D., Faloona, I., Simpas, J. B., Brune, W., Olson, J., Crawford, J., Avery, M., Sachse, G., Vay, S., Sandholm, S., Guan, H.-W., Vaughn, T., Mastromarino, J., Heikes, B., Snow, J., Podolske, J., and Singh, H.: $\mathrm{OH}$ and $\mathrm{HO}_{2}$ in the tropical Pacific: Results from PEM-Tropics B, J. Geophys. Res., 106, D23, doi:10.1029/2001JD900002, 2001.

Tie, X., Madronich, S., Walters, S., Zhang, R., Rasch, P., and Collins, W.: Effects of clouds on photolysis and oxidants in the troposphere, J. Geophys. Res., 108, 4642, doi:10.1029/2003JD003659, 2003.

Toon, O. B., McKay, C. P., Ackerman, T. P., and Santhanan, K. L.: Rapid calculation of radiative heating rates and photodissociation rates in inhomogeneous multiple scattering atmospheres, J. Geophys. Res., 94, 16287-16301, 1989.

Tripoli, G. and Cotton, W.: The Colorado State University threedimensional cloud-mesoscale model. Part I: General theoretical framework and sensitivity experiments, J. Res. Atmos., 16, 185219, 1982.

Von Glasow, R. and Crutzen, P. J.: Troposheric halogen chemistry, Treatise on Geochemistry update 1, edited by: Holland, H. D. and Turekian, K. K., Elsevier-Pergamon Oxford, 4.02, 1-67, 2007.

Walko, R. L., Cotton, W. R., Meyers, M. P., and Harrington, J. Y.: New RAMS cloud microphysics parameterization, Part I: the single-moment scheme, Atmos. Res., 38, 29-62, 1995.

Walko, R., Band, L., Baron, J., Kittel, F., Lammers, R., Lee, T., Ojima, D., Pielke, R., Taylor, C., Tague, C., Tremback, C., and Vidale, P.: Coupled atmosphere-biophysics-hydrology models for environmental modeling, J. Appl. Meteorol., 39, 931-944, 2000.

Wang, T. X., Kelley, M. D., Cooper, J. N., Beckwith, R. C., and Margerum, D. W.: Equilibrium, Kinetic, and UV-spectral characteristics of aqueous bromine chloride, bromine, and chlorine species, Inorg. Chem., 33, 5872-5878, 1994.

Wesely, M. L.: Parametrization of surface resistances to gaseous dry deposition in regional scale numerical models, Atmos. Environ., 23, 1293-1304, 1989.

Yang, X, Cox, R. A., Warwick, N. J., Pyle, J. A., Carver, G. D., O'Connor, F. M., and Savage, N. H.: Tropospheric bromine chemistry and its impact on ozone: A model study, J. Geophys. Res., 110, D23311, doi:10.1029/2005JD006244, 2005.

Yokouchi, Y., Hasebe, F., Fujiwara, M., Takashima, H., Shiotani, M., Nishi, N., Kanaya, Y., Hashimoto, S., Fraser, P., ToomSauntry, D., Mukai, H., and Nojiri, Y.: Correlations and emission ratios among bromoform, dibromochloromethane, and dibromomethane in the atmosphere, J. Geophys. Res., 110, D23309, doi:10.1029/2005JD006303, 2005.

Zhang, K., Wan, H., Zhang, M., and Wang, B.: Evaluation of the atmospheric transport in a GCM using radon measurements: sensitivity to cumulus convection parameterization, Atmos. Chem. Phys., 8, 2811-2832, doi:10.5194/acp-8-2811-2008, 2008. 